To be presented in AEA 2013

\title{
Debt Deflation Effects of Monetary Policy*
}

\author{
Li Lin ${ }^{\ddagger}$, Dimitrios P. Tsomocos *and Alexandros Vardoulakis ${ }^{\S}$
}

First version: January 2010

This version: January 2012

\begin{abstract}
This paper assesses the role that monetary policy plays in the decision to default using a General Equilibrium model with collateralized loans, trade in fiat money and production. Longterm loans are backed by collateral, the value of which depends on monetary policy. The decision to default is endogenous and depends on the relative value of the collateral to the loan. Default results in foreclosure, higher borrowing costs, inefficient investment and a decrease in total output. We focus on monetary shocks and assess the default channel affecting output using the intuition from Fisher's debt deflation theory.
\end{abstract}

\footnotetext{
${ }^{*}$ Acknowledgments: We are grateful to the seminar participants for their helpful comments in Banque de France, the Bank of Korea, the Mini Conference on Economic Theory in the University of Illinois, the 7th Annual Cowles Conference on General Equilibrium and its Application in Yale University, the 11th SAET Conference in Faro, the 43rd MMF Conference in Birmingham Business School. and to Fernando Alvarez, Regis Breton, Gael Giraud, Christian Hellwig, Charles Goodhart and Herakles Polemarchakis for their helpful comment. However, all remaining errors are ours.

†Said Business School and St. Catherine’s College, Oxford University, United Kingdom; email: li.lin@sbs.ox.ac.uk

${ }^{*}$ Said Business School and St. Edmund Hall, Oxford University, United Kingdom; email: dimitrios.tsomocos@sbs.ox.ac.uk

${ }^{\S}$ Banque de France, Paris, France; email: alexandros.vardoulakis@banque-france.fr

The views expressed in this paper are those of the authors and do not necessarily represent those of the Banque de France.
} 


\section{Keywords:}

Default, Collateral, Debt-deflation

JEL Classification: 


\section{Introduction}

Economic recessions, i.e. GDP contraction, have been studied thoroughly within the Real Business Cycle paradigm. The underlying intuition is that they are caused by adverse productivity shocks. The role of monetary policy is to stabilize prices and the function of the financial sector to facilitate the transfer of funds from depositors to entrepreneurs and the production sector. This literature has traditionally assumed that explicit modeling of banking activity was unnecessary, since it is commonly concluded that monetary policy and its effect on credit extension are neutral in the long-run.

The purpose of this paper is to examine the effects of monetary policy on total output within a framework of fully flexible prices. The underlying friction is that we allow agents to (endogenously) default on their long-term loan obligations. Thus, the need for collateral to back these loans arises. In all other respects, we maintain all the structural characteristics of General Equilibrium analysis, i.e. optimizing behavior, perfectly competitive markets and rational expectations. An advantage of our model is that it yields closed-from results. Hence, we are able to identify clearly the propagation mechanism and present the unfolding of events, through which monetary policy affects the decision to default and subsequently the allocation of capital and total output. To that extent we do not engage in a detailed discussion of optimal monetary policy, but rather propose default as an additional channel for affecting aggregate output.

The financial crisis of 2007 and its subsequent adverse effect on GDP has been a vivid example that requires a new methodological approach. The RBC literature cannot adequately address the issues arising from this crisis, since it is challenging, if not impossible , to justify that a recession preceded the large number of mortgage defaults and the subsequent pessimism in the banking sector that resulted in credit contraction. It would require a nontrivial degree of irrationality, since expectations had been very optimistic. ${ }^{1}$ Canonical DSGE models face the same inadequacy, since they have not paid much attention on credit frictions, heterogeneity and most importantly the possibility of endogenous default.

On the contrary, it was mortgage defaults and the adverse effect on banks capital that caused economic slowdown and the near financial meltdown. This view of economic recessions is not new. Its origin can be traced back in 1933, when Irving Fisher advocated his Debt Deflation theory of Great Depressions. His analysis is based on two fundamental principles,

\footnotetext{
${ }^{1}$ This view is shared among others by Robert Shiller (2005). The term "irrational exuberance" derives from some words that Alan Greenspan, chairman of the Federal Reserve Board in Washington, used in a black-tie dinner speech entitled " The Challenge of Central Banking in a Democratic Society". He then posed the question, "But how do we know when irrational exuberance has unduly escalated asset values, which then become subject to unexpected and prolonged contractions as they have in Japan over the past decade?". He added that "We as central bankers need not be concerned if a collapsing financial asset bubble does not threaten to impair the real economy, its production, jobs and price stability." We choose not to follow this view in our analysis, since its conclusions with respect to regulation and welfare are arbitrary due to the problem of defining irrational expectations. Instead, we will follow a rational approach that is more in line with the RBC literature and from our point of view captures financial sophistication, competitive markets and expertise to a larger extent.
} 
over-indebtedness and deflation. He argued that over-indebtedness can precipitate deflation in future periods and subsequently liquidation of collateralized debt, since borrowers would rather default than honour their contractual obligations. Debt is denominated in nominal terms and thus is constant, whereas the value of the collateral that secures this debt depends on market forces and monetary aggregates in the economy. The main mechanism in action is the decrease in the relative price of the collateralized durable good with respect to the numeraire in the economy. This leads to debt liquidation, and, consequently, to fire sales which suppress the value of the collateral even further. Hence, the initial deflationary pressures are exacerbated and they precipate to even higher default, and, ultimately, to lower output. And, hence, exacerbates the initial deflationary pressure, which at the end is the primary cause of output reduction.

Our work relates to a separate strand in the literature that argues that the financial crisis and in particular defaults on financial contracts can lead to economic recessions. Bernanke (1983) established that the Great Depression can be better explained when one explicitly models banking behavior and introduces the concept of the balance sheet channel in the conduct of monetary policy. Bernanke and Gertler (1989) modeled a collateral-driven credit constraint, introducing strong informational asymmetries, whereby the firm is only able to obtain fully collateralized loans. Hence, the value of the firm assets has to be equal to or greater than the value of the loan. Due to the scarcity of assets and capital, the amount of credit to the firm shrinks in the presence of deflationary pressures on the prices of its assets. This introduces an external finance premium, which increases with a decrease in the relative price of capital. In turn, an increase in the cost of capital will result in a decrease in the marginal product and a reduction in GDP. They show that GDP and investment do not only depend on the fundamentals and productivity, but also on the soundness of the firms' financial situation, which is an important source of financial instability. We argue in this paper that informational asymmetries are not the crucial element for the financial situation of firms to result in GDP contraction. Instead, the possibility of positive default and asset liquidation provide the genesis of a chain reaction that weakens the stability of the financial system and results into lower production. More elaborate models on the finance premium can be found in Holmstrom and Tirole (1997), Bernanke, Gertler, and Gilchrist (1999), S. Rao Aiyagari and Gertler (1999), Narayana Kocherlakota (2000), Bolton and Freixas (2000), Cooley, Marimon and Quadrini (2004).

Bernanke (1983) analyzed the relative importance of monetary versus financial factors and concluded that monetary forces alone were quantitatively insufficient to explain the depth and the persistence of the Depression. However, the collapse of the financial system has been an important factor that can be attributed to higher defaults and more importantly to overly pessimistic expectations about future deliveries. Bernanke contradicted the view of Friedman and Schwartz (1963), who found a high positive correlation between money supply and output and concluded that the decline in the money stock was a substantial factor for the Depression. Bernanke and Gertler (1995) instead claimed that the Friedman and Schwartz approach treats the transmission of monetary policy as a "black box" and showed the existence of a credit channel. We argue that the Fisherian approach combines both lines of thought as a decrease in the money supply can lead to over-indebtedness, defla- 
tion, higher default and ultimately a crisis in the financial sector. When the money supply decreases, over-indebtness and deflation will usually ensue. The crucial point is whether deflation in the price of assets used as collateral can trigger default and consequently a financial crisis. Thus, we propose a "debt deflation" channel of monetary policy.

The analytical framework supporting Fisher's theory has not been adequately developed in the literature. The seminal work of Bernanke and Gelter (1989), which assumes fully collateralized loans, and Mendoza (2006), which introduces collateral constraints in an RBC model, have been attempts in this direction. Nevertheless, they neither explicitly model money nor do they allow for positive default in equilibrium ${ }^{2}$. This weakens their analysis and does not entail that recessions follow financial crises. Fisher's view is that although an equilibrium is "stable, after departure from it beyond certain limits, instability ensues[...] until a certain point is reached, when it breaks. This simile probably applies when a debtor gets "broke", or when the breaking of many debtors constitutes a "crash", after which there is no coming back to the original equilibrium". Consider the case where debt is fully collateralized and entrepreneurs never default, since the nominal value of their contractual obligation is less than the value of their pledged collateral. Assume also that there is an adverse future state of the economy whereby the value of their debt is equal to the value of their collateral, and, thus, the borrower is indifferent between default and fully repaying his loan. In other words, he is on-the-verge of defaulting. Any further adverse shock in the economy that reduces further the value of his collateral will inevitably provide him with an incentive to default, since the benefit from defaulting will exceed his cost. In such a situation, the impact of the real economy becomes evident. When the entrepreneur defaults he loses the capital asset he has pledged as collateral and, therefore, his production will decrease. Subsequently, he needs to attract new capital in the market under more stringent financial conditions. The upshot of the argument is that this process may lead to productive inefficiency due to capital reallocation to firms that are not debt or liquidity constrained, yet the marginal product of capital is lower.

In this paper, we try to model the aforementioned situation and show how an adverse monetary or fundamental (or expectational) shock in the present can lead to over-in-debtness and future deflation that in some state of the world can result in default, debt liquidation, fire sales, reallocation of capital and finally reduction in $\mathrm{GDP}^{3}$. The introduction of uncertainty is important in such a framework, since if agents are expected to default in every

\footnotetext{
${ }^{2}$ Bernanke, Gertler and Gilchrist (1999) consider a monetary economy along the lines of Dynamic New Keynesian models. However, they focus on real contracts and argue that the modeling of nominal ones is an important step for future research. In our work, nominal long-term loans play a crucial role, since their face value is invariant to deflationary pressures, while the value of collateral that backs them is not.

${ }^{3}$ Hyman Minsky (1992) also discusses this issue in the first theorem of his Financial Instability Hypothesis, which relies on Fisher's debt-deflation theory. He argues that "the economy has financing regimes under which it is stable, and financing regimes in which it is unstable [...] furthermore, if an economy with a sizable body of speculative financial units is in an inflationary state, and the authorities attempt to exorcise inflation by monetary constraint [...] units with cash flow shortfalls will be forced to try to make position by selling out position. This is likely to lead to a collapse of asset values". This statement lies in the heart of our thesis, and in complementary to Fisher's argument, as we examine how contractionary monetary policy can lead to defaults on collateralized loans and asset liquidation.
} 
eventuality in the future the credit market will collapse and one cannot adequately study the debt-deflation mechanism. Moreover, market incompleteness is central to our analysis, since agents cannot write comprehensive contracts and hedge the possibility of default. Herein, we will consider a two period economy and show under what conditions the system can move to a state which is characterized by defaults on collateralized loan obligations. We shall consider an economy with entrepreneurs in which agents both produce and consume. Agents engage into long-term borrowing to buy the productive assets, which they pledge as collateral to secure their loan. We focus on an entrepreneurial economy, since we want to avoid problems arising from the valuation of a firm in a stock market economy. These issues are not central to our study and do not alter the spirit of our thesis. The decision to default is endogenous and depends on the difference between the value of the collateral and the loan. Although we could consider a moneyless economy to show our argument we choose to introduce money to emphasize how a nominal shock, and not only a productivity shock, can lead to financial fragility and a reduction in GDP.

Our approach is related to the work on the debt deflation theory of Sudden Stops (Mendoza (2006, 2010), Mendoza and Smith (2006)). They introduce collateral constraints in an RBC model of a Small Open Economy to show that when debt is sufficiently high, an adverse productivity shock triggers the constraints and results in a fire-sales spiral, falling prices and a reduction in output. Our results point to the same direction, though contrary to them we consider a monetary economy with nominal contracts and focus on monetary shocks, which have not been studied in the literature as much. In addition, they do not allow for the possibility of default. The latter is crucial for our analysis, since it is the reason that capital gets reallocated to result in inefficient production. Due to fully flexible nominal prices, monetary policy only affects the price level in the final period and not the total output in the absence of default. However, default makes credit conditions more adverse and capital is not allocated efficiently. Thus, default may not be studied independently from credit and liquidity.

Our framework is rich enough to analyze productivity shocks as the cause of debt deflation. A number of papers model fire-sales due to adverse productivity or funding shocks to capture debt-deflationary effects on asset prices leading to loss spirals and financial instability. These include Shleifer and Vishny (1992), Kiyotaki and Moore (1997), Suarez and Sussman (1997), Kyle and Xiong (2001), Geanakoplos (2003, 2010), Gromb and Vayanos (2002), Morris and Shin (2004), Fostel and Geanakoplos (2008), Brunnermeier and Pedersen (2009). Adrian and Shin (2009) show this channel empirically for financial institutions. However, we choose to focus on the monetary channel, since it is the least explored in the literature.

The rest of the paper proceeds as follows. Section 2 presents the model, while section 3 discusses the equilibrium. Section 4 describes how monetary policy can cause default and how the latter results in higher borrowing costs, capital reallocation and lower output. Section 5 concludes. The proofs are relegated to the Appendix. 


\section{The Model}

We build a general equilibrium model where two types of agents interact to produce a consumption good. Agents are considered to be entrepreneurs, who both produce and consume the same good. Production happens through the utilization of another capital good, from which agents derive no utility at any point in time. Nonetheless, its price will be always positive in the beginning of every period, since it is essential for the production of the consumption good from which agents derive utility. An important consequence of default is the reallocation of resources. The agent that defaults loses the pledged collateral, which is put for sale in the market. Heterogeneity is an important factor, since it is the reallocation of collateral that results in lower aggregate output. In a general equilibrium framework, the market for the capital good clears and all capital will be used for production. Total output depends on the efficient use of capital, which means any additional unit should end up to the agent with the higher marginal productivity. However, in the presence of financing frictions capital may end up with the least productive agent, since he may not face these frictions. Moreover, since production takes time and receipts from the sale of goods are not immediately available, we need a short term capital market. This may bridge the gap between expenditures and receipts from sales. The transaction demand for money motive naturally emerges from the cash-in-advance constraint. Since capital is a durable good,in view of the inherent moral hazard problem of honoring long-term debt obligation, agents are required to pledge the capital they purchase as collateral. Finally, the introduction of uncertainty is crucial, since under certainty there would be no default. Without loss of generality, since collateral liquidation, in the case of default and reallocation, plays a crucial role for the determination of the aggregate output when the supply of capital is fixed, we allow for default in only some realizations in the future.

The possibility of default on the contractual obligations that an agent undertakes underscores the necessity for our cash-in-advance constraints. The interplay of liquidity and default justifies fiat money as the stipulated mean of exchange. Otherwise, the mere presence of a monetary sector without any possibility of endogenous default or any other friction in equilibrium would become a veil without affecting real trade and, eventually, final equilibrium allocation. Indeed, cash-in-advance constraints are the minimal institutional arrangement to capture a fundamental aspect of liquidity and how it interacts with default to affect the real economy.

To sum up, our minimal modeling characteristics are agents' heterogeneity, consumption and a durable capital good, a collateralized long-term loan and short-term loan markets, flexible prices, a monetary economy, uncertainty and incomplete markets. Even though complexity increases with the introduction of these characteristics, we are able to solve the model in closed-form and derive analytical results for our thesis. We now describe the model in a more rigorous manner. 


\subsection{The Economy}

We consider a two-period monetary general equilibrium model with production, where agents know the present $(t=0)$ but face an uncertain future $(t=1)$, when nature chooses one of the states of the world $s \in S=\{1,2\}$ with probability $\pi_{s}$. State 1 and 2 are otherwise the same except that there is a lower short-term money supply by the central bank in state 2 than in state $1^{4}$. Let $S^{*}=\{0\} \cup S$ be the set of all states. There are two goods in the economy. Good 1 is a commodity and is perishable. Good 2 is a capital good and is durable. Two heterogeneous agents, $a$ and $b$ trade these two goods. Agent $a$ has an endowment $e \in R_{++}$of the capital good at $t=0$, while the poor agent $b$ has zero endowment of the capital good at every point in time. Agents are not endowed with the commodity good, but rather use capital to produce it. Agents obtain utility from consuming the commodity, while the capital has no consumption value and is only used for production. Let $x_{s^{*}}^{h}$ be the consumption of commodity in state $s^{*}$ by agent $h \in H$. For the purpose of finding a closed form solution, we assume a logarithmic utility function $\checkmark\left(x_{s^{*}}^{h}\right)=\ln \left(x_{s^{*}}^{h}\right): R_{+} \rightarrow R, \forall s^{*} \in S^{*}, h \in H$. Let $y_{s^{*} 2}^{h}$ be the capital good held by agent $h$ at the end of state $s^{*}$. Both agents have Cobb-Douglas production functions given by $F_{s^{*}}^{h}\left(y_{s^{*} 2}^{h}\right)=A_{s^{*}}^{h}\left(y_{s^{*} 2}^{h}\right)^{\sigma}: R_{+} \rightarrow R, \forall s^{*} \in S^{*}, h \in H$, where $A_{s^{*}}^{h}$ is the total factor productivity and $\sigma$ is the output elasticity of capital. Without loss of generality, we let both states occur with equal probability (i.e. $\pi_{1}=\pi_{2}=1 / 2$ ), and assume $A_{s^{*}}^{h}=1, \forall s^{*} \in S^{*}, h \in H, \sigma=0.3$ and $e=2^{5}$.

\subsection{Money, Short-term Money Markets, and Money Storage}

Money in our model is the stipulated means of exchange and a store of value. We introduce it through cash-in-advance constraints, such that an agent can purchase either the capital or the commodity in the relevant markets only by paying in money. Although money is fiat and has no intrinsic (consumption) value, it has value because it is essential for the conduct of transactions in the goods' markets. Agents cannot print their own money and they have to borrow it from the Central Bank, which intervenes directly in the short-term and long-term money markets. In particular, when the central bank purchases intra-period bonds within each state of the world, it injects a quantity of money $M_{s^{*}}, \forall s^{*} \in S^{*}$ into the system. Moreover, when the central bank extends a collateralized loan at $t=0$, it injects a quantity of money $\bar{m}$ into the system ${ }^{6}$. Money exits the system when agents repay their

\footnotetext{
${ }^{4}$ We can consider this as a monetary shock. This is the only source of uncertainty in the model. Alternatively, we could have distinguished the two states via a productivity shock. What matters is that there is some fundamental uncertainty between the two states, thus our results would be qualitatively the same under a productive shock as well.

${ }^{5}$ See lemma 4.2 and Proposition 4.9

${ }^{6}$ Collateralized long-term loan extension is not an unusual function of modern central banks especially in the aftermath of the 2007 financial crisis. Alternatively, one could think of government sponsored institutions, which extend collateralized loans, e.g. Freddie Mac or Fannie Mae in the case of mortgages. Abstracting from a competitive optimizing banking sector allows us to focus on the effects of credit extension/money supply by the central bank on default and output. However, by doing so we cannot derive conclusions about financial fragility and the possibility of credit crunches, which issues are kept for further research.
} 
short-term and long-term loan to the central bank. At the end of period 2 all money will exit the system, since it has no consumption value for any agent.

For $s^{*} \in S^{*}$, let $\mu_{S^{*}}^{h}$ be the amount of fiat money that agent $h$ chooses to owe in the short-term money market and $r_{s^{*}}$ be the short-term interest rate. From market clearing, we have that $1+r_{s^{*}}=\sum_{h \in H^{\prime}} \mu_{s^{*}}^{h} / M_{s^{*}}$. Thus, the ratio of nominal value of loans over the central bank's credit extension determines the gross nominal interest rate. The amount of fiat money that each agent $h$ borrows is $\mu_{s^{*}}^{h} /\left(1+r_{s^{*}}\right)$. Agents are not allowed to default in the short-term money markets.

The only way for agents to transfer money across periods is through a money storage technology. Agent $a^{7}$ may store $d$ amount of money in the beginning of $t=0$ so that he will be able to use it at $t=1$. Note that the money storage technology is only available at the beginning of $t=0$, not in the end of $t=0$.

\subsection{Commodity and capital good markets}

For $s^{*} \in S^{*}, p_{s^{*} 1}$ is the price of the commodity and $p_{s^{*} 2}$ is the price of capital. These are taken as exogenously given by both agents to maintain price-taking behavior. Let $b_{s^{*} 1}^{h}$ and $b_{s^{*} 2}^{h}, \forall h \in H$, be the amount of fiat money spent by agent $h$ to trade in the commodity and capital goods' markets in state $s^{*} \in S^{*}$. In addition, let $q_{s^{*} 1}^{h}$ and $q_{s^{* 2}}^{h}$ be the amount of commodity and capital offered for sale in state $s^{*} \in S^{*}$ by $h$. In equilibrium, at positive levels of trade, $0<p_{s^{*} 1}=\sum_{h \in H} b_{s^{*} 1}^{h} / \sum_{h \in H} q_{s^{*} 1}^{h}<\infty$, and $0<p_{s^{*} 2}=\sum_{h \in H} b_{s^{*} 2}^{h} / \sum_{h \in H} q_{s^{*} 2}^{h}<\infty$. Note that agents cannot sell commodities or capital goods they do not own.

The amount of capital good held by agent $a$ at the end of $t=0$ is $y_{02}^{a}=e-q_{02}^{a}$, while in state $s$ it is $y_{s 2}^{a}=e-q_{02}^{a}-q_{s 2}^{a}{ }^{8}$. The amount of capital good held by agent $b$ at the end of $t=0$ is $y_{02}^{b}=b_{02}^{b} / p_{02}$, while in state $s$ agent $b^{\prime} s$ final holdings depend on whether he defaults on the collateralized loan or not, which is discussed in the following section.

As mentioned, all transactions are intermediated through the use of fiat money, i.e. the proceeds from commodity sales in state $s^{*}$ can not be used to purchase the capital good directly, and vice versa. This institutional arrangement is a fundamental feature of a model that captures the importance of liquidity constraints and generates a transaction demand for fiat money. We have chosen to introduce money in our model through cash-in-advance constraints as it is methodologically convenient and captures the way goods prices are determined through the Quantity Theory of Money (QTM), whereby both prices and quan-

\footnotetext{
${ }^{7}$ In our model only agent $a$ stores money in, however, in principle the arrangement described here applies to agent $b$ as well; the same goes for the next section where we only describe agent $b$ taking out a collaterlized loan.

${ }^{8}$ We have modeled agent $a$ selling the capital good in both periods. In the initial period, this is always true since he is the only one endowed with it. However, it may well be the case that he buys back some capital in the second period. If this was the case $q_{s 2}^{a}$ would be negative and the cash-in-advance constraints would need to be adjusted accordingly. Note that this does not affect the results of our thesis.
} 
tities are affected when monetary variables change ${ }^{9}$. Cash-in-advance constraints should be viewed as liquidity constraints that distinguish goods from liquid wealth.

An alternative way to introduce a demand for money, is by incorporating money balances in the utility and production function. Stein (2010) considers such a model where banks engage in money creation and show that this can lead to financial instability due to fire-sales. When banks try to retain the riskless character of their IOUs, they will need to liquidate a part of their portfolio in bad realizations. Although in his model prices are flexible, monetary policy can play a role through controlling money creation. The reason is that money enters as an input in the objective function of both households and firms function. In our framework, the only role for money aggregates is to determine the price level of goods through the QTM. A change in the quantity of money will have no real effect on output in the final period if agents choose not to default on their long-term obligations. The only effect would be an adjustment in prices, since prices are fully flexible. However, the money stock in the initial period affects the investment decision by agent $b$. This is another financing friction due to the fact that the long-term loan needs to be backed by collateral. Given the scarcity of collateral, a change in $M_{0}$ will affect investment decisions. Thus, monetary policy in our models has real effects even in the absence of default in the first period. ${ }^{10}$ If deflationary pressures due to a lower money supply induces agents to default after a certain point, which results in a reallocation of resources, then monetary policy has real effects as well. We call this the debt deflation channel of monetary policy, which is described in detail in section 4 . We discuss the endogenous decision of agents to default in the following section. Recapitulatively, our debt deflation channel is initiated via positive default, thus emphasizing the important interconnection of liquidity and default. Consequently, the externality induced by positive default leads to inefficient capital allocation and investment in the economy.

\subsection{Default and Collateralized Loan}

In the initial period, agent $b$ finances his investment in the capital good both through shortterm and collateralized borrowing. When he borrows from the collateralized loan market ${ }^{11}$, he pledges the capital purchased as collateral. In the second period, the borrower either delivers in full the amount of the collateralized loan or defaults. In the case of default, the collateral pledged is foreclosed and is put for sale in the secondary capital market. The receipts are transferred to the central bank and determine the effective return on the collat-

\footnotetext{
${ }^{9}$ The methodology is close to Dubey and Geanakoplos (2006), Tsomocos (2003) and Goodhart et al. (2004, 2006, 2010a), who introduce cash-in-advance constraints to examine the interaction between liquidity and default and analyze financial stability. However, only Goodhart et al. (2010b) examine the interaction between money and collateral values in the case of mortgages.

${ }^{10}$ Lin (2010) shows explicitly that monetary policy is non-neutral even in the absence of default.

${ }^{11}$ As mentioned the price of the capital good will be higher than the the proceeds for goods sales, since it is durable and can be used for production in the second period as well. Thus, agent $b$ will partially finance his capital good's purchases through short-term borrowing or equivalently his income from goods sales within the same period, and partially through a long-term loan agreement. Since interest rates are endogenously determined, they will adjust to mirror his portfolio choice.
} 
eralized loan.

Formally, at $t=0$, agent $b$ takes out a collateralized loan to finance the purchase of the capital good. The interest rate is $\bar{r}$ and he promises to payback $\bar{\mu}$ in the next period. The collateralized loan extension is therefore $\bar{m}=\bar{\mu} /(1+\bar{r})$, since the credit extension is $\bar{m}$. He spends $b_{02}^{b} \leq \bar{\mu} /(1+\bar{r})+\mu_{0}^{b} /\left(1+r_{0}\right)^{12}$ amount of money to purchase $b_{02}^{b} / p_{02}$ amount of the capital good, which he then pledges as collateral. We denote by $C$ the amount of collateral pledged in terms of units of the capital good, i.e.C $=b_{02}^{b} / p_{02}$. Thus the collateralized loan is defined by both the interest rate and the collateral requirement. At $t=1$, the agent will deliver min $\left(\bar{\mu}, p_{s 2} C\right)$. If $p_{s 2} C \geq \bar{\mu}$, then agent $b$ does not default on the collateralized loan and delivers the full amount $\bar{\mu}$. This is not a naive assumption. Due to our General Equilibrium framework every contract is priced in equilibrium. When equilibrium prices are such that the value of the collateral in the future is less than the amount the agent has to repay, he would rather default, purchase the same amount of capital from the secondary market and be better off ${ }^{13}$. Default is an endogenous decision stemming from utility optimization. Only when equilibrium prices are such that the value of the collateral is higher than the nominal value of the loan will the agent repay fully. This is the debt deflation channel through which monetary policy and money supply matter for the determination of asset prices, such as the interest rate on the collateralized loan, and they affect the decision to default and aggregate output, which is analyze thoroughly in section 4 .

Moreover, agent $b$ spends an additional amount of money $b_{s 2}^{b}$ in the capital market at $\mathrm{t}=1$, which brings his final capital good's holdings to $y_{s 2}^{b}=b_{02}^{b} / p_{02}+b_{s 2}^{b} / p_{s 2}{ }^{14}$. When $p_{s 2} C<$ $\bar{\mu}$, the borrower will give up the collateral $C$, which is then sold on the market for $p_{s 2} C$. He will then spend $b_{s 2}^{b}$ to purchase the capital good and his holding is $y_{s 2}^{b}=b_{s 2}^{b} / p_{s 2}$.

\subsection{Time-structure of the markets}

At $t=0$, the short-term (intra-period) money and collateralized loan markets open. Then commodity and capital good markets meet. Agents produce within the period. Settlements of short-term loans occur at the end of each period. Finally, consumption takes place. The same market activities take place at $t=1$ in all the states and in addition agent $b$ repays the collateralized loans or alternatively defaults and pledged collateral is foreclosed.

${ }^{12}$ The ratio $\frac{\mu_{0}^{b} /\left(1+r_{0}\right)}{b_{02}^{b}}$ determines the margin on the collateralized loan, i.e. how much individual resources agent $b$ has to utilize to purchase the capital good. The lower the margin, the easier for the agent to purchase capital by using it as collateral.

${ }^{13} \mathrm{An}$ implicit assumption is that the agent is not further penalized for defaulting apart from losing the capital good his owns. Given that there is additional punishment, the wedge between the loan and the collateral value has to be higher for him to default. Such an assumption only adds complexity and does not alter the mechanism through which money supply affects the decision to default.

${ }^{14}$ In principle, the agent may choose to sell some of the capital good he owns in the second period. In this case, $b_{s 2}^{b}$ is negative and the cash-in-advance constraints need to be adjusted accordingly. Again this does not affect the results of our thesis. 
Figure 1 indicates the time line, including the moments at which the various markets meet. We make the sequence precise when we formally describe the budget set.

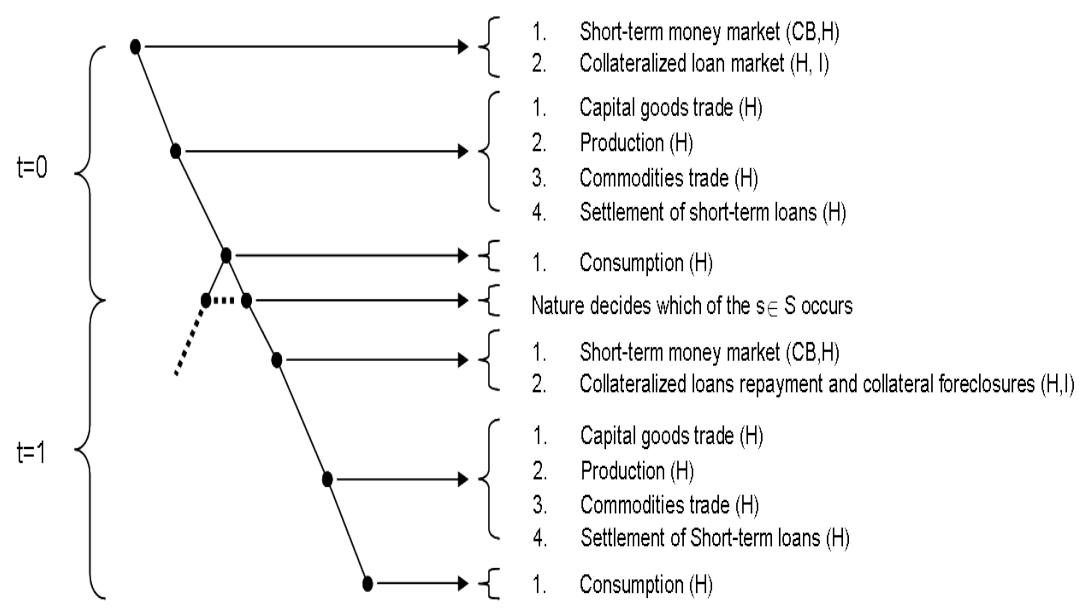

Figure 1: Time Structure

\subsection{Budget sets}

Denote the macro variables which are determined in equilibrium, and which every agent regards as fixed, by $\boldsymbol{\eta}=(\boldsymbol{p}, \boldsymbol{r}, \bar{r}) \in R_{+}^{2 S^{*}} \times R_{+}^{S^{*}} \times R_{+}$. Denote $\boldsymbol{\sigma}^{a} \in \sum_{a}(\boldsymbol{\eta})$, where $\boldsymbol{\sigma}^{a}=$ $\left(\boldsymbol{b}^{a}, \boldsymbol{q}^{a}, \boldsymbol{\mu}^{a}, d\right) \in R_{+}^{S^{*}} \times R_{+}^{S^{*}} \times R_{+}^{S^{*}} \times R_{+}$and $\boldsymbol{\sigma}^{b} \in \sum_{b}(\boldsymbol{\eta})$, where $\boldsymbol{\sigma}^{b}=\left(\boldsymbol{b}^{b}, \boldsymbol{q}^{b}, \boldsymbol{\mu}^{b}, \bar{\mu}\right) \in R_{+}^{S^{*}} \times$ $R_{+}^{S^{*}} \times R_{+}^{S^{*}} \times R_{+}$the vectors of agent $a$ and $b$ 's market decisions.

Agent $a$ 's optimization problem is as follows

$$
\begin{aligned}
& \max _{\boldsymbol{\sigma}^{a} \in \Sigma_{a}} \Pi^{a}=\ln \left(x_{0}^{a}\right)+\sum_{s \in S} \pi_{s} \ln \left(x_{s}^{a}\right) \\
& \text { s.t. } B^{a}(\boldsymbol{\eta})=\left\{\boldsymbol{\sigma}^{a} \in \sum_{a}(\boldsymbol{\eta}):\left(01^{a}\right)-\left(s 2^{a}\right)\right\}
\end{aligned}
$$

Agent $a$ faces the following constraints:

$$
\begin{array}{ll}
\left(01^{a}\right) & b_{01}^{a}+d \leq \frac{\mu_{0}^{a}}{1+r_{0}} \\
\left(02^{a}\right) & \mu_{0}^{a} \leq p_{02} q_{02}^{a} \\
\left(s 1^{a}\right) & b_{s 1}^{a} \leq \frac{\mu_{s}^{a}}{1+r_{s}}+d \\
\left(s 2^{a}\right) & \mu_{s}^{a} \leq p_{s 2} q_{s 2}^{a}
\end{array}
$$

$\left(01^{a}\right)$ says that in the beginning of $t=0$, agent $a$ borrows short-term to purchase commodities and deposits the rest. $\left(02^{a}\right)$ says that in the end of $t=0$, agent $a$ repays the short-term loan using the proceeds of capital sales. $\left(s 1^{a}\right)$ says that in the beginning of each state $s \in S$, agent $a$ uses the deposits and short-term borrowing to purchase the commodity. $\left(s 2^{a}\right)$ says that in the end of each state $s \in S$, agent $a$ repays the short-term loan 
using the proceeds of capital sales. The capital owned by agent $a$ in the end of each period is $y_{02}^{a}=e-q_{02}^{a}$ and $y_{s 2}^{a}=e-q_{02}^{a}-q_{s 2}^{a}$ respectively, as discussed in section 2.3. Note that agent $a$ can not sell more of the capital good than what he initially owns, i.e. $q_{02}^{a}<e$, $q_{s 2}^{a}<y_{02}^{a} . \quad x_{s^{*}}^{a}=\left(y_{s^{*} 2}^{a}\right)^{\sigma}+b_{s^{*}}^{a} / p_{s^{*}}$ is agent $a$ 's consumption, which is equal to what he produces plus the (net) purchases of the commodity.

Agent $b$ 's optimization problem is as follows:

$$
\begin{aligned}
& \max _{\boldsymbol{\sigma}^{b} \in \boldsymbol{\Sigma}_{b}} \Pi^{b}=\ln \left(x_{0}^{b}\right)+\sum_{s \in S} \pi_{s} \ln \left(x_{s}^{b}\right) \\
& \text { s.t. } B^{b}(\boldsymbol{\eta})=\left\{\boldsymbol{\sigma}^{b} \in \sum_{b}(\boldsymbol{\eta}):\left(01^{b}\right)-\left(s 2^{b}\right)\right\}
\end{aligned}
$$

Agent $b$ faces the following constraints:

$$
\begin{aligned}
& \left(01^{b}\right) \quad b_{02}^{b} \leq \frac{\mu_{0}^{b}}{1+r_{0}}+\frac{\bar{\mu}}{1+\bar{r}} \\
& \left(02^{b}\right) \quad \mu_{0}^{b} \leq p_{01} q_{01}^{b} \\
& \left(03^{b}\right) \quad C=\frac{b_{02}^{b}}{p_{02}} \\
& \left(s 1^{b}\right) \quad \bar{\mu}+b_{s 2}^{b} \leq \frac{\mu_{s}^{b}}{1+r_{s}} \quad \text { if b does not default in state } s \\
& \left(s 1^{b}\right) \quad b_{s 2}^{b} \leq \frac{\mu_{s}^{b}}{1+r_{s}} \quad \text { if } \mathrm{b} \text { defaults in state } s \\
& \left(s 2^{b}\right) \quad \mu_{s}^{b} \leq p_{s 1} q_{s 1}^{b}
\end{aligned}
$$

$\left(01^{b}\right)$ says that in the beginning of $t=0$, agent $b$ enters both a short-term and a collateralized loan to purchase the capital good. $\left(02^{b}\right)$ says that in the end of $t=0$, agent $b$ repays the short-term loan using the proceeds of commodity sales. $\left(03^{b}\right)$ says that agent $b$ puts all the capital good it bought as collateral for the intertemporal loan. $\left(s 1^{b}\right)$ says that in the beginning of each state $s \in S$, agent $b$ borrows short-term to purchase more of the capital good and also to repay the collateralized loan if he chooses not to default. If he chooses to default, he does not repay the collateralized loan and uses the money borrowed shortterm only to purchase capital, since the capital he owned has been seized and put for sale. $\left(s 2^{b}\right)$ says that in the end of each state $s \in S$, agent $b$ repays the short-term loan using the proceeds of the commodity sales. $x_{s^{*}}^{b}=\left(y_{s^{*} 2}^{b}\right)^{\sigma}-q_{s^{*}}^{b}$ is agent $b$ 's consumption, which is equal to the amount of the commodity he produces minus what he sells to repay his shortterm loan. The capital owned by agent $b$ in the end of each period is $y_{02}^{b}=b_{02}^{b} / p_{02}$ at $t=0$, $y_{s 2}^{b}=b_{02}^{b} / p_{02}+b_{s 2}^{b} / p_{s 2}$ in state $s$ if $b$ does not default and $y_{s 2}^{b}=b_{s 2}^{b} / p_{s 2}$ in state $s$ if $b$ chooses to default. 


\section{Equilibrium}

We say that $\left(\boldsymbol{\eta},\left(\boldsymbol{\sigma}^{h}\right)_{h \in H}\right)$ is a Monetary Collateral Equilibrium (MCE) for the economy $E\{v, e, F ; \boldsymbol{M}, \bar{m}\}$, iff:

(i) $\quad p_{s^{*} 1}=\frac{b_{s^{*} 1}^{a}}{q_{s^{*}}^{b}}, \quad \forall s^{*} \in S^{*}$

(ii) $\quad p_{02}=\frac{b_{02}^{b}}{q_{02}^{a}}$

$\left(i i^{\prime}\right) \quad p_{s 2}=\frac{b_{s 2}^{b}}{q_{s 2}^{a}} \quad$ if $b$ does not default in state $s \in S$

$\left(i i^{\prime \prime}\right) \quad p_{s 2}=\frac{b_{s 2}^{b}}{q_{s 2}^{a}+C} \quad$ if $b$ defaults in state $s \in S$

(iii) $1+\bar{r}=\frac{\bar{\mu}}{\bar{m}}$

(iv) $1+r_{s^{*}}=\frac{\sum_{h \in H} \mu_{s^{*}}^{h}}{M_{s^{*}}} \quad \forall s^{*} \in S^{*}$

(v) $\boldsymbol{\sigma}^{h} \in \underset{\boldsymbol{\sigma}^{h} \in B^{h}(\boldsymbol{\eta})}{\operatorname{argmax}} \Pi^{h}$

Condition ( $i$ ) says that the commodity market clears. Conditions $(i i),\left(i i^{\prime}\right)$ and $\left(i i^{\prime \prime}\right)$ say that the capital good markets clear for all $s^{*} \in S^{*}$. Condition (iii) says that the collateralized loan market clears. Condition (iv) says that the short-term money markets clear. Condition (v) says that both agents optimize. In sum, all markets clear, expectations are rational, i.e. future prices and interest rates are correctly anticipated, and agents optimize given their budget sets.

Lemma 3.1. Binding Budget Constraints. All the constraints $\left(s^{*} 1^{h}\right)$ and $\left(s^{*} 2^{h}\right), \forall s^{*} \in$ $S^{*}, h \in H$ are binding.

Lemma 3.2. Given an CME, there exists another CME with the same prices, interest rates, amounts of consumptions and quantities of production factors in which no agent acts on both side of any market.

To facilitate our analysis and derive closed form solutions we need to ensure that there are no wash sales in equilibrium. Hence, we analyze equilibria where agents do not sell and buy the same good simultaneously, and they do not borrow and lend at the same money market or mortgage market.

Since agent $b$ is not endowed with capital and agent $a$ has a decreasing return to scale production function, there will always exist gains from trade. Thus, agent $a$ will sell part of his capital endowment to $b$ and subsequently buy back some of $b$ 's output. If there is no default, all interest rate will be equal to zero (see proposition 4.4). Consequently, there will always be an equilibrium with positive trade among agents. Even in the case when there is 
default, the short term interest rate in the future period will be positive in the default state (see proposition 4.6). Given that agent $b$ has no capital in either future state it will be optimal to borrow and default in the collateralized money market and, consequently, borrow in the second period short-term loan market so as to buy the capital good and produce the consumption good. Thus, regardless of the level of the interest rate in the second period, there will always be gains from trade.

Note that even if we did not have money, the fact that the "security" facilitating the sale of the capital good is collateralized places an endogenous bound on short sales. Hence, an equilibrium always exists, since prices of the collateral are bounded.

\section{Proposition 3.1. Determinacy.}

Let $M_{0}$ be such that $\frac{2 \bar{m}}{M_{1}+\bar{m}}<q_{02}^{a}<\frac{2 \bar{m}}{M_{2}+\bar{m}}$. Then, for an open, dense, and full measure $E \in \boldsymbol{E}\left((v, e, F)_{h \in H} ; M_{0}, M_{1}, M_{2}, \bar{m}\right)$ the set of $C M E$ is finite.

As the previous proposition shows, when there is no default the CME manifests nominal indeterminacy despite the presence of collateral. Hence, liquidity does not affect real allocations and investment decisions. Put differently, if we double, for example all the money supplies in all the short term and mortgage markets then by doubling all prices we maintain the same equilibrium allocation. This observation underlines the interconnectedness of liquidity and default. The critical factor for nominal determinacy is the presence of liquid wealth. This occurs either in the form of private monetary endowments as in Dubey and Geanakoplos (1992) (i.e. positive liquid wealth) or positive default as in Shubik and Tsomocos (1992) (i.e. negative liquid wealth). Thus, when liquid wealth is zero there do not exist any wealth effects and, therefore, the classical dichotomy obtains. In other words, the real and the nominal sectors of the economy do not interact. ${ }^{15}$

\section{Debt Deflation Channel of Monetary Policy}

The main objective of this paper is to characterize the debt deflation channel of monetary policy. As already mentioned, we want to examine the way that the money stock matters for the aggregate output level. Given that we have abstracted from any other financial frictions apart from default and since prices are flexible, for the most part monetary policy will only affect the general price level, while production will be efficient if there is no default. The money supply in the initial period affects the allocation of capital and total output at $\mathrm{t}=0$, while the latter is maximized at $\mathrm{t}=1$ given that no default occurs in any state of the world. This is the conclusion of proposition 4.5. To reach this conclusion we solve for the agents' optimal production decision in proposition 4.3 and show that there is a wedge between the marginal productivity of the two agents, which is a function of the short-term interest rate. Proposition 4.1 models the term-structure of interest rates and proposition 4.4 solves for the interest rates when there is no default in equilibrium.

\footnotetext{
${ }^{15}$ This is also akin to the fiscal theory of price (see Buiter (1999)).
} 
In this paper, we aim to treat debt-deflation as a monetary phenomenon. We show that a lower circulation of money in the first period leads to debt-deflation in the second period. We also show default inefficiency. The aim of this paper can be described in the following three steps. First, we want to examine the relationship between monetary policy in $t=0$ and agent $b$ 's decision to default (Proposition 4). Will a contractionary money supply in the initial period lead to default in the next period? Second, we want to see how money supply and default lead to a change in interest rates (Proposition 4.6). Due to cash-in-advanced constraints, interest rates are the "price" for liquidity, and they play an important role in the allocation of the capital good. Finally, we want to study the effects of interest rate variations on total production in $t=1$ due to monetary policy change and subsequent default by agents (Proposition 4.7).

In our model, the motives for holding money are crucial for the existence of equilibrium. Fiat money is the stipulated means of exchange, and it is exchanged for the acquisition of capital and commodities, while receipts from sales are used to pay back loans and possibly transfer wealth from one period to the other. However, we maintain all the structural characteristics of rational expectations modeling and since money does not enter into the utility function, agents will not hold money idle in the end. All available liquidity will be channeled in the capital and commodity markets at $t=1$. This means that all the central bank money supply (i.e. $M_{0}, M_{1}, M_{2}, \bar{m}$ ) would exit the system via short-term and collateralized loan repayments. This is captured by proposition 4.1. However, at $t=0$ due to missing financial markets agents may opt to hold precautionary savings, to hedge against future uncertainty.

Proposition 4.1. Term Structure of Interest Rates. At $t=0$, the aggregate money that exits the system is equal to the short-term loan repayment at $t=0$ plus any precautionary saving, while the aggregate money that enters the system is equal to the collateralized loan extension by the central bank plus the short-term loan credit extension. At $t=1$, the aggregate money that exits the system is equal to the repayment on the short-term and collateralized loans, while the aggregate money that enters the system is equal to the precautionary savings plus the short-term loan extension. Thus,

$$
\text { (4.11) } M_{0} r_{0}+d=\bar{m}
$$

$$
\begin{aligned}
& M_{1} r_{1}+\min \left[p_{12} C, \bar{\mu}\right]=d \\
& M_{2} r_{2}+\min \left[p_{22} C, \bar{\mu}\right]=d
\end{aligned}
$$

The above proposition shows that the liquidity provision by the central bank and the default decision by agent $b$ may produce an intricate relationship among interest rates. Two important aims of our paper are to examine how liquidity and default affect interest rates ${ }^{16}$, and how aggregate output fluctuates with interest rate levels.

\footnotetext{
${ }^{16} \mathrm{We}$ consider liquidity to be the ability to borrow in the short-term loan markets. When the interest rate is higher, it is more costly to borrow money and liquidity is lower.
} 
Nevertheless, our thesis suggests that not only the interest rate, but also the quantity of money are important for the determination of the price and output levels. The quantity theory of money (Proposition 4.2) provides the intuition for the result. Reducing the quantity of money at $\mathrm{t}=0$ does not only affect prices, but also quantities sold, since it has an effect on the ability of the poor in capital agent to leverage up and purchase capital (unlike the representative agent's sell-all assumption). This, in turn, affects the price of capital in the second period, since the quantity sold will depend on the stock of the durable good that agents hold from the previous period.

Proposition 4.2. Quantity Theory of Money Proposition. In a MCE, the aggregate income at $t=0$, namely the value of all capital good and commodity sales, is equal to the sum of total short-term credit and collateralized loan extension provided by the central bank minus the precautionary savings. In state $s$ at $t=1$, if agent $b$ does not default, aggregate income equals the sum of total short-term central bank money supply and of precautionary savings minus the collateralized loan repayment. If agent $b$ defaults, aggregate income equals the sum of total short-term central bank money supply and of precautionary savings. The QTM holds for each point in time. In particular,

period 0 ,

$$
p_{01} q_{01}^{b}+p_{02} q_{02}^{a}=M_{0}+\bar{m}-d
$$

period 1 ,

if agent $b$ does not default in state s:

$$
p_{s 1} q_{s 1}^{b}+p_{s 2} q_{s 2}^{a}=M_{s}+d-\bar{\mu}
$$

if agent $b$ defaults in state $s$ :

$$
p_{s 1} q_{s 1}^{b}+p_{s 2}\left(q_{s 2}^{a}+C\right)=M_{s}+d
$$

\subsection{Interest rates and Production}

We first show how individual production varies with the interest rate level (lemma 4.1) and finally how the latter affects the allocation of capital and aggregate output (Proposition 4.3). We then distinguish between the default and no default cases. Proposition 4.4 solves for the interest rate in the case of no default, whereas proposition 4.6 corresponds to the case where default is present in equilibrium. Under no default production will be efficient/optimal in the last period (Proposition 4.5). As already discussed, production will not be optimal at $\mathrm{t}=0$ and will depend on the available liquidity at that point in time, i.e. $M_{0}$. We show later that monetary policy in the initial period can increase aggregate output, but at the same time affect prices as well. It is the credit friction of collateralized loans that allows this relationship to exists. When agent $b$ chooses to default, capital gets reallocated and production seizes to be optimal even in the last period. This inefficiency of default is shown in proposition 4.7. The inefficiency stems from a change in interest rates, which creates a wedge between buying and selling capital (Proposition 4.6). In section 4.2 we show how contractionary monetary policy can create debt deflationary pressures in the value of collateral, which result in default in the last period and a reduction in aggregate output. 
In the following lemma, we formally examine the impact of money stock on production via interest rate changes. The agent who demands the capital good will purchase it from the agent who is rich in it, financing his purchase partly with short-term credit. A change in the price of short-term credit will have an impact on the trade of capital goods, thus it will affect the allocation of capital good and output.

Lemma 4.1. Relative prices, allocations and short-term interest rates. For agent $b$ who borrows in the short-term money market, purchases capital goods and sells commodities, we have:

at $t=0$

$$
\frac{\left[\frac{1}{x_{0}^{b}} B_{0} \sigma\left(y_{02}^{b}\right)^{\sigma-1}+\pi_{1} \frac{1}{x_{1}^{b}} B_{1} \sigma\left(y_{12}^{b}\right)^{\sigma-1}+\pi_{2} \frac{1}{x_{2}^{b}} B_{2} \sigma\left(y_{22}^{b}\right)^{\sigma-1}\right]}{\frac{1}{x_{0}^{b}}}=\frac{p_{02}\left(1+r_{0}\right)}{p_{01}}
$$

at $t=1, \forall s \in S$

$$
\left(4.12^{*}\right) \frac{\frac{1}{x_{s}^{b}} B_{s} \sigma\left(y_{s 2}^{b}\right)^{\sigma-1}}{\frac{1}{x_{s}^{b}}}=\frac{p_{s 2}\left(1+r_{s}\right)}{p_{s 1}}
$$

For agent a who borrows in the short-term money market, purchases commodities and sells capital goods, we have:

at $t=0$

$$
\frac{\left[\frac{1}{x_{0}^{a}} A_{0} \sigma\left(y_{02}^{a}\right)^{\sigma-1}+\pi_{1} \frac{1}{x_{1}^{a}} A_{1} \sigma\left(y_{12}^{a}\right)^{\sigma-1}+\pi_{2} \frac{1}{x_{2}^{a}} A_{2} \sigma\left(y_{22}^{a}\right)^{\sigma-1}\right]}{\frac{1}{x_{0}^{a}}}=\frac{p_{02}}{p_{01}\left(1+r_{0}\right)}
$$

at $t=1, \forall s \in S$

$$
\left(4.14^{*}\right) \frac{\frac{1}{x_{s}^{a}} A_{s} \sigma\left(y_{s 2}^{a}\right)^{\sigma-1}}{\frac{1}{x_{s}^{a}}}=\frac{p_{s 2}}{p_{s 1}\left(1+r_{s}\right)}
$$

Equation $\left(4.11^{*}\right)$ shows the trade-off between purchasing capital goods and selling commodities. The numerator of the LHS is the marginal utility of agent $b$ from the use of the durable capital to produce commodities. The denominator of the LHS is the marginal utility of his consumption. The RHS is the relative price of the capital good and commodity, including the interest rate wedge, since the purchase of the capital good is financed by short-term borrowing and thus is costly. The same discussions follow for the other three equations.

The above lemma 4.1 shows that interest rates have intricate effects on the allocation of commodity and capital good, as well as production and final consumption. To the aim of this paper, we are particularly interested in how interest rate variation affects the allocation of capital good and total production, which is examined in the following proposition.

Proposition 4.3. Interest Rate's Redistribution Effect on Capital Good. At $t=1$, there is 
an interest rate wedge between the marginal productivity of agent $a$ and agent $b$.

$$
\frac{B_{s} \sigma\left(y_{s 2}^{b}\right)^{\sigma-1}}{A_{s} \sigma\left(y_{s 2}^{a}\right)^{\sigma-1}}=\left(1+r_{s}\right)^{2}
$$

The change of $r_{s}, s \in S$ is positively related to the change of $y_{s 2}^{a}$ and negatively related to the change of $y_{s 2}^{b}$.

Both agents produce using the capital good. Agent $a$, who is rich in it, does not need to purchase any capital and thus avoids the financing cost. Agent $b$, who purchases capital, borrows short-term and has to pay the financing cost. The interest rate acts as a wedge between the marginal productivities of the two agents. In other words, there is a financing premium. When the interest rate increases, it is more expensive for agent $b$ to purchase the capital good. An increase in the marginal productivity of agent $b$ is needed to compensate for the higher financing cost, otherwise it would not be profitable to purchase an additional unit. Due to a concave production function, this results in a lower capital input for agent $b$. Since the total amount of the capital good is fixed in the economy, agent $a$ will hold more of it after an increase in the interest rate. Proposition 4.3 shows that an increase in the interest rate in state $s$ will redistribute capital from the (initial) buyer to the (initial) seller due to the interest rate wedge between the marginal productivity of the seller and the buyer.

Hence, the level of the interest rate determines the allocation of capital. When agent $b$ does not default on his obligations, all interest rates are zero as shown in the following proposition.

Proposition 4.4. Interest Rates under no default. When agent $b$ does not default on the collateralized loan, the interest rates on short-term loans and the collateralized loan are all equal to zero, i.e. $r_{s^{*}}=0, \forall s^{*} \in S^{*}$ and $\bar{r}=0$.

This proposition says that, if there is no default, all interest rates and the collateralized loan rate are zero, even if the central bank alters the money supply. This is contradictory with reality where money supply has an inverse relationship with interest rate. The intuition is as follows. In the end of $t=0$ both agents will repay all their short-term debts in full. In the end of $t=1$ both agents will repay all their short-term loans and the collateralized loan fully. The total amount of repayment in the two periods, including principal and interest, is $M_{0}\left(1+r_{0}\right)+M_{s}\left(1+r_{s}\right)+\bar{m}(1+\bar{r})$. The total amount of money available for them to repay (i.e. all the money available in the system) is equal to total amount of money supply injected by the central bank, i.e. $M_{0}+M_{s}+\bar{m}$. In the absence of default, only when all interest rates and the collateralized loan rate are zero will the money available be sufficient for agents to fulfill their obligations. Since they do not have monetary endowment themselves, the only way possible to repay each loan is to pay back an amount exactly equal to what they borrowed.

Given that short-term interest rates are zero, we can conclude from proposition 4.3 that production is efficient and total output is maximized in the last period. 
Proposition 4.5. Optimal Production in the Absence of Default. Assume $A_{s}=B_{s}$. If agent $b$ does not default on the collateralized loan, the production in the economy is optimized at $t=1$.

Due to cash-in-advance constraints, agent $b$ who is short in capital in period $t=1$ needs to borrow short-term to finance additional purchases of capital. When there is no default and the interest rate is zero, there is no financing cost and the economy allocates capital efficiently. In other words, there is no interest rate wedge between the marginal productivities in the last period. The marginal productivities of the two agents are therefore the same, which results in optimal production and maximum aggregate output. Otherwise, it is always welfare improving to transfer some of the capital from one agent to the other. This is not the case in the initial period regardless of the zero interest rate wedge. As it will be more obvious in section 4.2 , the money stock at $t=0$ affects the quantity of the capital good sold due to the financing friction introduced by the need for collateral.

We now turn to the determination of the interest rates under the presence of default and show the inefficiency in production that default yields.

Proposition 4.6. Interest Rates Under Default. Consider an equilibrium in which agent $b$ defaults on the collateralized loan in state 2 , but not in state 1 . Then, the short-term interest rate in state 2 is positive, i.e. $r_{2}=\frac{\bar{m}-p_{22} C}{M_{2}}>0$, while the short-term interest rates at $t=0$ and in state 1 , and the collateralized loan rate are all equal to zero, i.e. $r_{0}=0, r_{1}=1$ and $\bar{r}=0$.

We can see that when agent $b$ defaults in state 2 (and does not do so in state 1), the shortterm interest rate is no longer zero. Agent $b$ defaults and the collateral is foreclosed and sold. The proceeds go to the central bank as a form of repayment. However, this repayment is not in full, so there is some money left in the system. As we discussed above, in the end all money will exit the system, hence the extra money left in the system will exit as an additional interest payment for the short-term credit provided by the central bank. The intuition is that when agent $b$ decides to default, the central bank can not do anything except foreclosing the collateral, which is less valuable than the full payment of collateralized loan. To compensate for the money lost in the collateralized loan extension, the central bank will charge a positive interest rate on the short-term credit as a penalty for default. We now show the inefficiency that a positive interest rate brings in production due to default.

Proposition 4.7. Suboptimal Production in the presence of default. When agent $b$ defaults on the collateralized loan, production in the economy is not efficient.

We can see that after default, although all the capital good is still fully utilized, it is not allocated in an optimal way. Due to a positive financing cost, capital is no longer allocated efficiently. The positive interest rate acts as a wedge between the two agents' marginal productivities, so that agent $a$ has a lower productivity than agent $b$, or agent $b$ ends up holding less capital good than agent $a$. It is welfare improving to transfer some capital from agent $a$ to agent $b$, since $b$ has a higher marginal productivity. The total production in the economy is reduced due to the inefficiency that default brings along. 


\subsection{Contractionary Monetary Policy and Default}

In this section we study the endogenous decision to default and examine when agent $b$ decides to default on the collateralized loan. It is a market consensus that agent will default and surrender the collateral when the value of collateral is lower than the value of loan. The following proposition offers economic intuition on agent's decision on default.

Proposition 4.8. Marginal Decision of Default Agent $b$ will marginally default on the collateralized loan when the marginal gain from default equals to the marginal loss from default. Formally, we have:

$$
\frac{\left(1+r_{s}\right)\left(\bar{\mu}-b_{s 2}^{b}\right)}{p_{s 1}} \frac{1}{x_{s 1}^{b}}=\left(C-\frac{b_{s 2}^{b}}{p_{s 2}}\right) B_{s} \sigma\left(y_{s 2}^{b}\right)^{\sigma-1} \frac{1}{x_{s 1}^{b}}
$$

The LHS is the marginal gain from default. If the agent $b$ defaults on the mortgage loan, then it does not pay $\bar{\mu}$ and it will spend $b_{s 2}^{b}$ to purchase some capital good after foreclosure. So agent $b$ will end up having an increment of money amount equals to $\left(\bar{\mu}-b_{s 2}^{b}\right)$. Since cash-in-advance constraint is assumed, agent $b$ needs to borrow $\left(\bar{\mu}-b_{s 2}^{b}\right)$ less amount of short-term credit to repay the inter-temporal loan. This means that it will sell $\left(1+r_{s}\right)\left(\bar{\mu}-b_{s 2}^{b}\right) / p_{s 1}$ less amount of commodity to repay the loan. This means that it will have an incremental utility of $\left(1 / x_{s 1}^{b}\right)\left(1+r_{s}\right)\left(\bar{\mu}-b_{s 2}^{b}\right) / p_{s 1}$.

The RHS is the marginal loss from default. In default, agent $b$ losses the collateral $C$ and then buys back some $b_{s 2}^{b} / p_{s 2}$ amount of capital. However, he can not buy back all of them, so he has $\left(C-b_{s 2}^{b} / p_{s 2}\right)$ amount less of capital, evaluated at the marginal utility obtained from the commodity produced by capital $\operatorname{good} B_{s} \sigma\left(y_{s 2}^{b}\right)^{\sigma-1}\left(1 / x_{s 1}^{b}\right)$.

One of the purpose of this paper is to study the relationship between the money supply and the default condition. The following provides a formal study on this topic. To simplify the proof, from now on we assume $A_{s}=B_{s}, e=2, \sigma=0.3$, and $M_{s^{*}}>\bar{m}, \forall s^{*} \in S^{*}$. We first derive the necessary conditions for agent $b$ to default (lemma 4.2) and then show how contractionary monetary policy can lead to this condition. Given the production inefficiency that default brings along (Proposition 4.7), we prove the existence of a suboptimal equilibrium due to debt deflationary pressures in proposition 4.9.

Lemma 4.2. Default Condition. Consider an equilibrium where agent $b$ does not default on the collateralized loan. We say that he is on the verge of defaulting if $q_{02}^{a}=\frac{2 \bar{m}}{M_{2}+\bar{m}}$ and will start defaulting if $q_{02}^{a}<\frac{2 \bar{m}}{M_{2}+\bar{m}}$.

This lemma provides the equilibrium solution for the default condition that an agent will default on the collateralized loan if the collateral is less valuable than the amount of loan. It says that when the capital good sold by agent $a$ in $t=0$ (equivalent to the capital good purchased by agent $b$ in $t=0$ ) is lower than a certain threshold specified by the fundamentals of the economy, then agent $b$ will default on the collateralized loan. Answering the question whether monetary policy has an impact on the default decision is equivalent to 
seeing whether there is a money supply such that $q_{02}^{a}$ is smaller than this threshold. This is examined in the following proposition.

Proposition 4.9. Debt deflation channel of Monetary Policy. Consider an equilibrium where agent $b$ does not default on the collateralized loan. Then, $\frac{\partial q_{02}^{a}}{\partial M_{0}}>0$. Also, $\exists M_{0}^{*}$, such that $q_{02}^{a}=\frac{2 \bar{m}}{M_{2}+\bar{m}}>\frac{2 \bar{m}}{M_{1}+\bar{m}}$ and for $M_{0}<M_{0}^{*}$ agent $b$ starts defaulting in state 2. Finally, default occurs due to debt deflationary pressures on the price of the collateral, since $p_{22}=b_{22}^{b} /\left(1-y_{02}^{b}\right)=\left(M_{2}-\bar{m}\right) /\left(2\left(1-q_{02}^{a}\right)\right)$ and $\frac{\partial p_{22}}{\partial M_{0}}>0$.

This proposition shows that in an initial equilibrium where agent $b$ does not default in either state, there is a positive relation between the money supply at $t=0$ and $q_{02}^{a}$. When the money supply at $t=0$ is reduced, $q_{02}^{a}$ goes down as well. Also, there is a certain money supply $M_{0}^{*}$ at which $q_{02}^{a}$ reaches the default threshold in state 2 , but not in state 1 where there is a relatively higher money supply. In another words, agent $b$ is on the verge of default in state 2 . This proposition says that a contractionary monetary policy in $t=0$ will lead agent $b$ into default in state 2 .

Since $\frac{\partial q_{02}^{a}}{\partial M_{0}}>0$, we can see that when the central bank reduces the money supply in period $t=0$, agent $b$ purchases less capital. However, agent $b$ will still borrow the same amount of collateralized loan, $\bar{m}$, extended by the central bank. Thus, the same amount of collateralized loan is backed by less capital, or equivalently leverage is higher or the margin is lower. Moreover, we can see that with a lower $q_{02}^{a}$, the price of the capital good in state $s$, $p_{s 2}=b_{s 2}^{b} /\left(1-y_{02}^{b}\right)=\left(M_{2}-\bar{m}\right) /\left(2\left(1-q_{02}^{a}\right)\right)$, is lower. To sum up, a lower money supply in $t=0$ leads to a lower $q_{02}^{a}$ and a lower $p_{s 2}$. Since the default decision in state $s$ is given by $p_{s 2} C<\bar{m}$, which is equivalent to $p_{s 2} q_{02}^{a}<\bar{m}$, we can see that a lower $M_{0}$ will drive agent $b$ closer to default. In fact, lemma 4.2 points out that when $q_{02}^{a}$ is reduced to a certain point, it will lead agent $b$ into default in state $s$. Proposition 4.9 shows that when the money supply in $t=0$ is lower, agent $b$ is closer to default. When the money supply is reduced to $M_{0}^{*}$, agent $b$ is on the verge of defaulting in state 2 , since $q_{02}^{a}=2 \bar{m} /\left(M_{2}+\bar{m}\right)$, but agent $b$ will still be away from default in state 1 , since $q_{02}^{a}>2 \bar{m} /\left(M_{1}+\bar{m}\right)$. When the central bank reduces the money supply even more, then agent $b$ will start defaulting in state 2 .

The above lemma 4.2 and proposition 4.9 show debt-deflation and default as monetary phenomena: a lower circulation of money in the first period leads to debt-deflation in the second period. We proxy the circulation of money with money supply. The debt-deflation here means relative deflation, i.e. a lower ratio of collateral value to the corresponding loan value. It shows that a decreasing money supply by the central bank in the first period leads to a lower ratio of collateral value to the corresponding loan value in the second period monotonically, i.e. there is a positive correlation between the money supply at $t=0$ and the ratio of collateral value to loan value at $t=1$. The lower the money supply, the lower the ratio of collateral value to loan value. We coined this term "relative deflation." The lemma 4.2 points out the condition for default. When a money supply is reduced to a certain point, the ratio of collateral value to the loan value is equal to one. If the money supply is 
reduced further, the value of the collateral is less than the loan value, and the agent finds it profitable to default on the loan repayment. This is what we call a debt deflation channel of monetary policy, since in the presence of default capital gets reallocated and aggregate output decreases.

\section{Conclusion}

In this paper, we build a monetary general equilibrium model with collateral and production and have a formal treatment of the Fisher debt-deflation effects of monetary policy. We see that the usual propositions in monetary general equilibrium model hold in this model, namely the quantity theory of money and the term structure of interest rate. Since this is a model with production, we also show that money and interest rates have an effect on total production (real output). One important result of this model is that interest rate as the cost of financing has a redistribution effect on the investment. When the interest rate is higher, then the capital good will be redistributed from more productive agents to less productive ones. Another special property of the model is the marginal default decision. Although it is a consensus that agents will default when the value of collateral is less than the contractual obligation, we see that agent is marginally indifferent if the marginal gain from default is equal to the marginal loss from default. The marginal loss is the marginal utility of the output that could have been produced by the collateral lent due to default.

We argued that Fisher debt-deflation is, in principle, a monetary phenomenon. We examined how a negative shock in money supply in the initial period lead to default in the second period through over-indebtedness and deflation. Following Fisher, the two dominant diseases for debt-deflation is too-much debt (in our case high leverage) and subsequent deflation. We show that when the central bank reduces the short-term money supply in the first period, the leverage ratio in that period increases: the agent still borrows the same amount of collateralized loan while put less amount of capital good as collateral. Furthermore, when the initial money supply is reduced, we find that the price of the collateral (i.e. the capital good) is lower in the second period. The higher leverage and deflation are the lower ratio of collateral value to loan value becomes in the second period and this brings the agent closer to default. In fact, we find when the money supply in the initial period is lower than a threshold level, agents will default. If initially the agent does not default and the money supply is close to the threshold, then a small negative money supply shock creates relative deflation and generates default.

One would imagine that if an economy is at is potential output, then it would not matter significantly whether or not there is default. However, this turns out not to be the case. In our model, the other important result is that after default, the interest rate in state 2 increases significantly, which results in a redistribution of capital good from the more productive firm to the less productive one. The production in state 2 is reduced and deviates from optimal production. These variations in interest rate, investment and output do not have significant impact in an equilibrium without default. Note that agent's default creates an externality to the economy by driving the short-term interest rate up that finally results into output 
contraction.

The model shows the debt-deflation argument and default inefficiency in a context of a monetary collateral equilibrium with production. The upshot is that, given all the production factors are fully utilized after debt-deflation, we still manage to show the reduction in production and the misallocation of resources. That is, we allow agent $b$ to bid for the capital good in the market. Alternatively, had we put $b$ into bankruptcy and forbid him from any further activities, then all the production factor will be in the hand of agent $a$ and the adverse effect on total production will be even worse. This is where we differentiate ourselves from Fisher's debt deflation theory. Recall, in his 1933 paper, Fisher considered the extreme case when defaulters get into bankruptcy after debt-deflation. This naturally leads to lower production since agents that default stop producing altogether. However, in our model, we manage to show inefficiency of the debt-deflation without forcing defaulters into bankruptcy. Here, all the production factors are still in use. The externality is that they are not used as optimally as previously. Indeed, due to the higher financing cost, the poor in capital agent produces less than the initially richer. Thus, deflation favors in a sense the "creditor" and harms the "debtor".

In sum, Fisher's debt deflation argument crucially depends on both liquidity and default as it is shown in proposition 4.9. It is precisely the interplay of liquidity and default that activates the default channel that distorts optimal capital investments.

\section{References}

[1] Adrian T. and Shin H. (2009), Money, Liquidity, and Monetary Policy, American Economic Review: Papers \& Proceedings 99(2), 600-605

[2] Aiyagari S.R. and Gertler M. (1999), Overreaction of Asset Prices in General Equilibrium, Review of Economic Dynamics 2(1), 3-35

[3] Benranke, B. (1983), Non-monetary effects of the financial crisis in propagation of the Great Depression, American Economic Review 73(2), 257-276

[4] Bernanke B. and Gertler M. (1989), Agency Costs, Net Worth and Business Fluctuations, American Economic Review 79(1), 14-31

[5] Benranke B. and Gertler M. (1995), Inside the black box: The credit channel of monetary policy transmission, Journal of Economic Perspectives 9(4), 27-48

[6] Bernanke B., Gertler M. and Gilchrist S. (1999), The Financial Accelerator in a Quantitative Business Cycle Framework, in Handbook of Macroeconomics. Volume 1C, ed. John B. Taylor and Michael Woodford, 1341-1393. Amsterdam: North-Holland 
[7] Bolton P. and Freixas X. (2000), Equity, bonds and bank debt: Capital structure and financial market equilibrium under asymmetric information, Journal of Political Economy 108(2), 324-351

[8] Brunnermeier M.K. and Pedersen L. (2009), Market Liquidity and Funding Liquidity, Review of Financial Studies 22(6), 2201-2238

[9] Buiter W.H. (1999), The Fallacy of the Fiscal Theory of the Price Level, CEPR Discussion Papers 2205

[10] Cooley T., Marimon R. and Quadrini V. (2004), Aggregate Consequences of Limited Contract Enforceability, Journal of Political Economy $112(4), 817-847$

[11] Dubey P. and Geanakoplos J. (1992), The Value of Money in a FiniteHorizon Economy: A Role for Banks, in P. Dasgupta, D. Gale, D. Hart, and E. Maskin (eds.), Economic Analysis of Markets and Games, Essays in Honor of Frank Hahn. Cambridge, MA: MIT Press, 407-444

[12] Dubey P. and Geanakoplos J. (2006), Determinacy with Nominal Assets and Outside Money, Economic Theory 27(1), 79-106

[13] Dubey P., Geanakoplos J. and Shubik M. (2005), Default and Punishment in General Equilibrium, Econometrica 73(1), 1-37

[14] Fisher I. (1933), The Debt-Deflation Theory of Great Depressions, Econometrica 1, 337-357

[15] Fostel A. and Geanakoplos J. (2008), Leverage Cycles and the Anxious Economy, American Economic Review 98(4), 1211-1244

[16] Friedman M. and Schwartz A. (1963), A monetary history of the United States, 1867-1960, Princeton, N.J.: Princeton University Press

[17] Geanakoplos J. (2003), Liquidity, Default, and Crashes: Endogenous Contracts in General Equilibrium, Advances in Economics and Econometrics: Theory and Applications, Eighth World Conference, Volume II, Econometric Society Monographs, 170-205

[18] Geanakoplos J. (2009), The leverage cycle, Cowles Foundation discussion paper

[19] Goodhart CAE, Sunirand P. and Tsomocos D. P. (2004), A Model to Analyse Financial Fragility: Applications, Journal of Financial Stability $1,1-30$

[20] Goodhart CAE, Sunirand P. and Tsomocos D.P. (2006a), A Model to Analyse Financial Fragility, Economic Theory 27, 107-142 
[21] Goodhart CAE, Tsomocos D.P., Peiris MU and Vardoulakis A.P. (2010a), On Dividend Restrictions and the Collapse of the Interbank Market, Annals of Finance 6(4), 455-473

[22] Goodhart CAE, Tsomocos D.P. and Vardoulakis A.P. (2010b), Modelling a Housing and Mortgage Crisis, in Financial Stability, Monetary Policy and Central Banking. Ed. C. Echeverria, R. Fuentes and D. Gray., Series on Central Banking, Analysis and Economic Policies. Central Bank of Chile

[23] Gromb D. and Vayanos D. (2002), Equilibrium and welfare in markets with financially constrained arbitrageurs, Journal of Financial Economics 66(2-3), 361-407

[24] Greenspan A. (1996), Remarks by Chairman Alan Greenspan at the Annual Dinner and Francis Boyer Lecture of the American Enterprise Institute for Public Policy Research, Washington, D.C. December 5, 1996

[25] Guembel A. and Sussman O.(2002), Liquidity, Contagion and Financial Crisis, working paper

[26] Hart O. and Moore J. (1998), Default and Renegotiation: A Dynamic Model of Debt, Quarterly Journal of Economics 113(1), 1-41

[27] Holmstrom B. and Tirole J. (1997), Financial Intermediation, Loanable Funds, and The Real Sector, The Quarterly Journal of Economics 112(3), 663-691

[28] King M. (1994), Debt deflation: Theory and evidence, European Economic Review 38, 419-445

[29] Kiyotaki N. and Moore J. (1997), Credit Cycles, Journal of Political Economy 105(2), 211 ï£;248

[30] Kocherlakota N. (2000), Creating Business Cycles Through Credit Constraints, Federal Reserve Bank of Minneapolis Quarterly Review 24(3), 2-10

[31] Kyle A.S. and Xiong W. (2001), Contagion as a Wealth Effect, Journal of Finance 56, 1401-1440

[32] Lin L.(2010), Monetary Collateral Equilibrium and Fisher Debtdeflation, Working Paper

[33] Mendoza E.G. (2006), Lessons from the Debt-Deflation Theory of Sudden Stops, American Economic Review 96(2), 411-416

[34] Mendoza E.G. (2010), Sudden Stops, financial crises and leverage, forthcoming American Economic Review 
[35] Mendoza E.G. and Smith K.A. (2006), Quantitative implications of a debt deflation theory of Sudden Stops and asset prices, Journal of International Economics 70, 82-114

[36] Morris S. and Shin H. (2004), Liquidity Black Holes, Review of Finance $8,1-18$

[37] Shiller R.(2005), Irrational Exuberance, 1st Edition, Princeton University Press 2000

[38] Shleifer A. and Vishny R.W. (1992), Liquidation Values and Debt Capacity: A Market Equilibrium Approach, Journal of Finance 47, 13431366

[39] Shubik M. and Tsomocos D.P. (1992), A strategic market game with a mutual bank with fractional reserves and redemption in gold: A continuum of traders, Journal of Economics 55(2), 123-150

[40] Stein J.C.(2010), Monetary Policy as Financial-Stability Regulation, working paper

[41] Suarez J. and Sussman O. (1997), Endogenous Cycles in a Stiglitz-Weiss Economy, Journal of Economic Theory 76, 47-71

[42] Tsomocos D.P. (2003), Equilibrium Analysis, Banking and Financial Instability, Journal of Mathematical Economics 5-6, 619-655

\section{Appendix}

Proof to lemma 3.1

Proof. Let $x_{0}^{a *}$ be the optimal consumption for agent $a$ in equilibrium. Assume that $\left(01^{a}\right)$ is not binding. There always exists a $x_{0}^{a} \in B^{a}$, where $x_{0}^{a}=x_{0}^{a *}+\varepsilon$ and $\varepsilon>0$, such that $x_{0}^{a}$ is preferable than $x_{0}^{a *}$ for agent $a$ - a contradiction with the optimality of $x_{0}^{a *}$. The proof for other binding constraints are on the same line.

Intuitive proof to the binding constraints when interest rate is zero. We have for agent $\alpha$

$\left(01^{a}\right) \quad b_{01}^{a}+d \leq \mu_{0}^{a}$

$\left(02^{a}\right) \quad \mu_{0}^{a} \leq p_{02} q_{02}^{a}$

$\left(s 1^{a}\right) \quad b_{s 1}^{a} \leq \mu_{s}^{a}+d$

$\left(s 2^{a}\right) \quad \mu_{s}^{a} \leq p_{s 2} q_{s 2}^{a}$

Constraint $\left(01^{a}\right)$ binds, since if it is not, agent $a$ would consume more or deposit more. Noted that wash sale is not allowed. (We can put lemma 3.2 before lemma 3.1) Agent $\alpha$ will not borrow more than necessary and transfer the cash flow WITHINE period (a within period deposit with zero interest rate. Since it generates same equilibrium allocation. See the proof for lemma 3.2). (that means, when agent $\alpha$ borrows short-term, then it must be used to deposit or purchase goods, otherwise he should not borrow short-term at all). 
Follow the same reason, constraint $\left(s 1^{a}\right)$ binds. Constraints $\left(02^{a}\right)$ and $\left(s 2^{a}\right)$ bind, otherwise agent $a$ can sell less.

We have for agent $\beta$

$\left(01^{b}\right) \quad b_{02}^{b} \leq \mu_{0}^{b}+\bar{\mu}$

$\left(02^{b}\right) \quad \mu_{0}^{b} \leq p_{01} q_{01}^{b}$

$\left(03^{b}\right) \quad C=\frac{b_{02}^{b}}{p_{02}}$

$\left(s 1^{b}\right) \quad \bar{\mu}+b_{s 2}^{b} \leq \mu_{s}^{b} \quad$ if b does not default in state $s$

$\left(s 1^{b}\right) \quad b_{s 2}^{b} \leq \mu_{s}^{b} \quad$ if b defaults in state $s$

$\left(s 2^{b}\right) \quad \mu_{s}^{b} \leq p_{s 1} q_{s 1}^{b}$

Follow the same reasoning, since there is no wash sale, if agent $b$ transfer cash INTRA period, then it must not borrow short-term. If agent $b$ transfers cash INTER period, it must not borrow long term. Since it borrowed both ST and LT, he should not transfer cash INTRA or INTER. Q.E.D

Proof to lemma 3.2

Proof. Suppose that $b_{s 1}^{h}, q_{s 1}^{h}>0$. Then either $r_{s}=0$ or $\mu_{s}^{h}=0$, otherwise since there is a price wedge between selling and purchasing with credit, $h$ will always be better off if he sets $q_{s 1}^{h}=0$ and borrows less credit. When $r_{s}=0$ or $\mu_{s}^{h}=0$ holds, if $\left(b_{s 1}^{h} / p_{s 1}-q_{s 1}^{h}\right)>0$ then set $q_{s 1}^{h}=0$ and $b_{s 1}^{h}=\left(x_{s 1}^{h}-y_{s 1}^{h}\right) p_{s 1}$. If $\left(b_{s 1}^{h} / p_{s 1}\right)-q_{s 1}^{h}<0$, then set $b_{s 1}^{h}=0$ and $q_{s 1}^{h}=y_{s 1}^{h}-x_{s 1}^{h}$. Further, let $h$ hoards all the unused money across all trading time and leave all of his other actions unchanged. Clearly, we get a CME with the same equilibrium outcomes. Similar proof apply for trade in capital goods.

Proof to proposition 3.1

Proof. By Lemma 3.1 all budget constraints are binding and no agent will be left with worthless cash at $t=1$. Given that $\frac{2 \bar{m}}{M_{1}+\bar{m}}<q_{02}^{a}<\frac{2 \bar{m}}{M_{2}+\bar{m}}$, from proposition 4.9 we see that agent $b$ defaults in state 2 while not default in state 1 . From proposition 4.6 , we get $r_{0}=0$ and $r_{2}>0$.

Now from our existence argument $p_{s l}>0, \forall l \in L$ and $s \in S$. Finally, from lemma 3.2, we can consider an equilibrium where no agent will act on both sides of the market.

The equations of an CME.

Let $\nabla_{s l}^{h} \equiv\left(\partial v^{h} / \partial x_{s l}^{h}\right)\left(x^{h}\right), \forall h \in H, s \in S$, where $x^{h}$ is the final consumption of $h$ at a CME under consideration. Also, let $\nabla_{F s}^{h} \equiv\left(\partial F / \partial y_{s}^{h}\right)\left(y_{s}^{h}\right), \forall h \in H, s \in S$, where $y_{s}^{h}$ is the input of production by $h$ at a CME.

NOTE: the $\frac{1}{x_{0}^{a}}, \frac{1}{x_{s}^{a}}$ are marginal utilities, which equivalent to $\nabla_{01}^{a}$ and $\nabla_{s 1}^{a}$ here.

For $t=0$ and $h=a$, by taking first order condition of agent $\alpha$ 's lagrangian problem with r.w.t $b_{01}^{a}, \mu_{0}^{a}$ and $q_{02}^{a}$, we have

$\left(0^{a}\right) \nabla_{01}^{\mathrm{a}} \frac{\mathrm{p}_{02}}{\mathrm{p}_{01}\left(1+\mathrm{r}_{0}\right)}-\nabla_{01}^{\mathrm{a}} \nabla_{\mathrm{F} 0}^{\mathrm{a}}-\pi_{1} \nabla_{11}^{\mathrm{a}} \nabla_{\mathrm{F} 1}^{\mathrm{a}}-\pi_{2} \nabla_{21}^{\mathrm{a}} \nabla_{\mathrm{F} 2}^{\mathrm{a}}=0$

by taking FOC w.r.t to $\bar{d}, b_{01}^{a}, b_{11}^{a}$ and $b_{21}^{a}$, we have

$\left(3^{a}\right) \nabla_{01}^{\mathrm{a}} \frac{1}{\mathrm{p}_{01}}-\sum_{\mathrm{s} \in \mathrm{S}} \pi_{\mathrm{s}} \nabla_{\mathrm{s} 1}^{\mathrm{a}} \frac{1}{\mathrm{p}_{\mathrm{s} 1}}=0$ 
For $s=1$ and $h=a$, we have

by taking FOC w.r.t. to $b_{11}^{a}, \mu_{1}^{a}$ and $q_{12}^{a}$

$\left(1^{a}\right) \nabla_{\mathrm{F} 1}^{\mathrm{a}}-\frac{\mathrm{p}_{12}}{\mathrm{p}_{11}\left(1+\mathrm{r}_{1}\right)}=0$

For $s=2$ and $h=a$, we have

by taking FOC w.r.t. to $b_{21}^{a}, \mu_{2}^{a}$ and $q_{22}^{a}$

$\left(2^{a}\right) \nabla_{\mathrm{F} 2}^{\mathrm{a}}-\frac{\mathrm{p}_{22}}{\mathrm{p}_{21}\left(1+\mathrm{r}_{2}\right)}=0$

Similarly, for $t=0$ and $h=b$, WHEN THRER IS NO DEFAULT, by taking first order condition of agent $b$ 's lagrangian problem with r.w.t $b_{02}^{b}, \mu_{0}^{b}$ and $q_{01}^{b}$, we have

$\left(0^{b}\right)\left(\nabla_{\mathrm{F} 0}^{\mathrm{b}} \nabla_{01}^{\mathrm{b}}+\pi_{1} \nabla_{\mathrm{F} 1}^{\mathrm{b}} \nabla_{11}^{\mathrm{b}}+\pi_{2} \nabla_{\mathrm{F} 2}^{\mathrm{b}} \nabla_{21}^{\mathrm{b}}\right) \frac{1}{\mathrm{p}_{02}\left(1+\mathrm{r}_{0}\right)}-\nabla_{01}^{\mathrm{b}} \frac{1}{\mathrm{p}_{01}}=0$

by taking FOC w.r.t to $\bar{\mu}_{b}, \mu_{0}^{b}, q_{01}^{b}, \mu_{1}^{b}, q_{11}^{b}, \mu_{2}^{b}$ and $q_{21}^{b}$, we have

$\left(3^{b}\right) \nabla_{01}^{\mathrm{b}} \frac{1}{\mathrm{p}_{01}}\left(1+\mathrm{r}_{0}\right)-(1+\overline{\mathrm{r}}) \sum_{\mathrm{s} \in \mathrm{S}} \pi_{\mathrm{s}} \nabla_{\mathrm{s} 1}^{\mathrm{b}} \frac{1}{\mathrm{p}_{\mathrm{s} 1}}\left(1+\mathrm{r}_{\mathrm{s}}\right)=0$

For $s=1$ and $h=b$, we have

by taking FOC w.r.t. $b_{12}^{b}, \mu_{1}^{b}$ and $q_{11}^{b}$

$\left(1^{b}\right) \nabla_{\mathrm{F} 1}^{\mathrm{b}} \frac{1}{\mathrm{p}_{12}\left(1+\mathrm{r}_{1}\right)}-\frac{1}{\mathrm{p}_{11}}=0$

For $s=2$ and $h=b$, we have

by taking FOC w.r.t. $b_{22}^{b}, \mu_{2}^{b}$ and $q_{21}^{b}$

$\left(2^{b}\right) \nabla_{\mathrm{F} 2}^{\mathrm{b}} \frac{1}{\mathrm{p}_{22}\left(1+\mathrm{r}_{2}\right)}-\frac{1}{\mathrm{p}_{21}}=0$

WHEN THRER IS DEFAULT, by taking first order condition of agent $b$ 's lagrangian problem with r.w.t $b_{02}^{b}, \mu_{0}^{b}$ and $q_{01}^{b}$, we have

$\left(0^{b}\right)\left(\nabla_{\mathrm{F} 0}^{\mathrm{b}} \nabla_{01}^{\mathrm{b}}+\pi_{1} \nabla_{\mathrm{F} 1}^{\mathrm{b}} \nabla_{11}^{\mathrm{b}}\right) \frac{1}{\mathrm{p}_{02}\left(1+\mathrm{r}_{0}\right)}-\nabla_{01}^{\mathrm{b}} \frac{1}{\mathrm{p}_{01}}=0$

by taking FOC w.r.t to $\bar{\mu}_{b}, \mu_{0}^{b}, q_{01}^{b}, \mu_{1}^{b}, q_{11}^{b}$, we have

$\left(3^{b}\right) \nabla_{01}^{\mathrm{b}} \frac{1}{\mathrm{p}_{01}}\left(1+\mathrm{r}_{0}\right)-(1+\overline{\mathrm{r}}) \pi_{1} \nabla_{11}^{\mathrm{b}} \frac{1}{\mathrm{p}_{11}}\left(1+\mathrm{r}_{1}\right)=0$

Therefore, typically, the number of active variables $=$ the number of equations, see Table 5 .

We now purturb each of the equation of $a$. To purturb $\left(0^{a}\right)$, adjust $\nabla_{F 0}^{a}$, which leaves the rest of the equations undisturbed. Next, consider $\left(1^{a}\right),\left(2^{a}\right)$ and $\left(3^{a}\right)$. By adjusting $\nabla_{F 1}^{a}, \nabla_{F 2}^{a}$ and $\nabla_{01}^{a}$ respectively, we disturb $\left(0^{a}\right)$. We restore this by further adjusting $\nabla_{F 0}^{a}$ in all cases. Consider the budget constraints, for $\left(01^{a}\right)$ that is binding, by adjusting $b_{0}^{a}$, we disturb $\left(01^{a}\right)$, to restore this we further adjust $\mu_{0}^{a}$ and we vary $M_{0}^{a}$ and maintain $r_{0}$ constant by adjusting appropriately $M_{0}$. Then adjust $p_{02}$ to restore $(02)^{a}$. Then adjust $\nabla_{F 0}^{a}$ to restore $(0)^{a}$ and adjust $\nabla_{F 0}^{b}$ to restore $(0)^{b}$. Thus, the rest of the equations are left undistrubed. Likewise for $\left(02^{a}\right)$. The same applies for the rest of the budget constraints of $a$. The analogous perturbations hold for $b$.

A standard transversality argument shows that the set of CME is finite. Remark: when there is no default in either state, then from proposition 4.4, $\bar{r}=r_{1}=r_{2}=r_{0}=0$, we can double $M_{0}, M_{1}, M_{2}$ and $\bar{m}$ and also all prices still satisfy all budget constraints.

Proof to proposition 4.1 


\begin{tabular}{ll}
\hline \hline Active Variables & Equations \\
\hline$q_{s^{* 1}}^{a}$ & $\left(s^{* a}\right)$ \\
$d$ & $\left(3^{a}\right)$ \\
$b_{s^{*} 1}^{a}$ & $\left(s^{*} 1^{a}\right)$ \\
$b_{s^{*} 2}^{a}$ & $\left(s^{*} 2^{a}\right)$ \\
$q_{s^{*} 1}^{b}$ & $\left(s^{* b}\right)$ \\
$\bar{\mu}$ & $\left(3^{b}\right)$ \\
$b_{s^{*} 1}^{b}$ & $\left(s^{*} 1^{b}\right)$ \\
$b_{s^{*} 2}^{b}$ & $\left(s^{*} 2^{b}\right)$ \\
\hline \hline
\end{tabular}

Proof. From the binding budget constraints $\left(01^{a}\right),\left(02^{a}\right),\left(01^{b}\right),\left(02^{b}\right)$ in lemma 3.1 and market clear conditions $p_{01}=b_{01}^{a} / q_{01}^{b}, p_{02}=b_{02}^{b} / q_{02}^{a}, 1+\bar{r}=\bar{\mu} / \bar{m}$ and $1+r_{0}=\left(\mu_{0}^{a}+\right.$ $\left.\mu_{0}^{b}\right) / M_{0}$, we have $M_{0} r_{0}+d=\bar{m}$; In state $s \in S$, if $\bar{\mu} \leq p_{s 2} C$, then agent $b$ does not default; from the binding budget constraints $\left(s 1^{a}\right),\left(s 2^{a}\right),\left(s 1^{b}\right),\left(s 2^{b}\right)$ and market clear conditions $p_{s 1}=b_{s 1}^{a} / q_{s 1}^{b}, p_{s 2}=b_{s 2}^{b} / q_{s 2}^{a}$ and $1+r_{s}=\left(\mu_{s}^{a}+\mu_{s}^{b}\right) / M_{s}$, we have $M_{s} r_{s}+\bar{\mu}=d$; if $p_{s 2} C<$ $\bar{\mu}$, then agent $b$ defaults; from the binding budget constraints $\left(s 1^{a}\right),\left(s 2^{a}\right),\left(s 1^{b}\right),\left(s 2^{b}\right)$ and market clear conditions $p_{s 1}=b_{s 1}^{a} / q_{s 1}^{b}, p_{s 2}=b_{s 2}^{b} /\left(q_{s 2}^{a}+C\right)$ and $1+r_{s}=\left(\mu_{s}^{a}+\mu_{s}^{b}\right) / M_{s}$, we have $M_{s} r_{s}+p_{s 2} C=d$. To sum up, we have $M_{s} r_{s}+\min \left[p_{s 2} C, \bar{\mu}\right]=d$.

Proof to proposition 4.2

Proof. The equation for $t=0$ comes from combiding the binding equation $\left(01^{a}\right)$ and $\left(01^{b}\right)$ and market clear conditions $p_{01}=b_{01}^{a} / q_{01}^{b}, p_{02}=b_{02}^{b} / q_{02}^{a}, 1+\bar{r}=\bar{\mu} / \bar{m}$ and $1+r_{0}=\left(\mu_{0}^{a}+\right.$ $\left.\mu_{0}^{b}\right) / M_{0}$. The proof for the other two equations are on the same line.

Proof to lemma 4.1

Proof. Equation $\left(4.11^{*}\right)$ comes from combining the first order conditions of agent $b$ 's optimization problem w.r.t. $b_{02}^{b}, \mu_{0}^{b}$ and $q_{01}^{b}$, we have :

$\lambda_{01}^{b}=\frac{1}{p_{02}}\left[\frac{1}{x_{0}^{b}} B_{0} \sigma\left(y_{02}^{b}\right)^{1-\sigma}+\pi_{1} \frac{1}{x_{1}^{b}} B_{1} \sigma\left(y_{12}^{b}\right)^{1-\sigma}+\pi_{2} \frac{1}{x_{2}^{b}} B_{2} \sigma\left(y_{22}^{b}\right)^{1-\sigma}\right], \frac{1}{x_{0}^{b}}=\lambda_{02}^{b} p_{01}, \frac{\lambda_{01}^{b}}{1+r_{0}}=$ $\lambda_{02}^{b}$ and . Likewise, we can get equations $\left(4.12^{*}\right),\left(4.13^{*}\right)$ and $\left(4.14^{*}\right)$ from other first order equations.

Proof to proposition 4.3

Proof. From the equations $\left(4.12^{*}\right)$ and $\left(4.14^{*}\right)$, we have $\left(B_{s} / A_{s}\right)\left(y_{s 2}^{b} / y_{s 2}^{a}\right)^{1-\sigma}=\left(1+r_{s}\right)^{2}$. Because $B_{s} / A_{s}$ is fixed and positive, when $r_{s}$ increases, we have $y_{s 2}^{b} / y_{s 2}^{a}$ reduces. Because $y_{s 2}^{b}+y_{s 2}^{c}=e$, we have $y_{s 2}^{b}$ increases and $y_{s 2}^{a}$ decreases.

Proof to proposition 4.4

Proof. Given that the short-term interest rates $r_{s^{*}} \geq 0, \forall s^{*} \in S^{*}$ and the collateralized loan rate $\bar{r} \geq 0$. When agent $b$ does not default on the collateralized loan in any state $s \in S$, then there must be $p_{s 2} C \geq \bar{\mu}$, with market clearing condition $1+\bar{r}=\bar{\mu} / \bar{m}$, equations (4.12) and (4.13) become

$$
\text { (4.41) } \quad M_{1} r_{1}+\bar{m}+\bar{m} \bar{r}=d
$$




$$
M_{2} r_{2}+\bar{m}+\bar{m} \bar{r}=d
$$

From (4.11), we can see $d \leq \bar{m}$ since otherwise $M_{0} r_{0}<0$. If $d<\bar{m}$, then from (4.41), we have $\bar{m} \bar{r}+M_{1} r_{1}=d-\bar{m}<0$, which contradicts with the fact tht $\bar{r} \geq 0$ and $r_{1} \geq 0$. So only $\bar{d}=\bar{m}$ is possible. Hence we have $M_{0} r_{0}=0$ and $M_{1} r_{1}+\bar{m} \bar{r}=0$. With the nonnegative interest rates, we can see that $r_{0}=0, r_{1}=0$ and $\bar{r}=0$. The proof for $r_{2}=0$ follows the same line.

Proof to proposition 4.5

Proof. When agent $b$ does not default, from proposition 4.3, we know that $\left(B_{s} / A_{s}\right)\left(y_{s 2}^{b} / y_{s 2}^{a}\right)^{1-\sigma}=$

1. We can see that $\left(y_{s 2}^{b} / y_{s 2}^{a}\right)^{1-\sigma}=A_{s} / B_{s}$. If the interest rate $r_{s}$ is not zero, let $y_{s 2}$ and $y_{s 2}^{\hat{a}}$ be the capital good owned by agent $b$ and $a$ in state $s$ respectively, then we have $\left(y_{s 2}^{\hat{b}} / y_{s 2}^{\hat{a}}\right)^{1-\sigma}=\left(A_{s} / B_{s}\right)\left(1+r_{s}\right)^{2}$. We have $\left(y_{s 2}^{\hat{b}} / y_{s 2}^{\hat{a}}\right)^{1-\sigma}>\left(y_{s 2}^{b} / y_{s 2}^{a}\right)^{1-\sigma}$. Thus we can see $\left(y_{s 2}^{b} / y_{s 2}^{\hat{a}}\right)<\left(y_{s 2}^{b} / y_{s 2}^{a}\right)$. Since $A_{s}=B_{s}, y_{s 2}^{a}+y_{s 2}^{b}=e$ and $y_{s 2}^{\hat{a}}+y_{s 2}^{\hat{b}}=e$, we have $y_{s 2}^{\hat{b}}<y_{s 2}^{b}=e / 2$ and $y_{s 2}^{a}>y_{s 2}^{a}=e / 2$. So when interest rate is positive, the capital good owned by agent $b$ is lower than the capital good owned by agent $a$, and the productivity of agent $b$ is higher than the productivity of agent $a$. We can always distribute some capital good from agent $a$ to agent $b$ to achieve higher total production. When the interest rate is zero, we can see that monetary policy, any of $M_{s^{*}}, \forall s^{*} \in S^{*}$ or $\bar{m}$ or the combination of the above, has no impact of the allocation of capital good in $t=1$. The capital good is evenly allocated to the two agents. Since the production function is concave, we can see that evenly distributed capitals good leads to the maximum production in the economy at $t=1$.

Proof to proposition 4.6

Proof. The proof for $r_{0}=0, r_{1}=0$ and $\bar{r}=0$ follow the proposition 4.4. Since agent $b$ defaults on the collateralized loan, with the market clear conditions $1+\bar{r}=\bar{\mu} / \bar{m}$, we have $p_{s 2} C<\bar{\mu}^{b}=\bar{m}(1+\bar{r})=\bar{m}$. From (4.13), we have $M_{2} r_{2}=\bar{d}-p_{s 2} C>\bar{d}-\bar{m}=0$, so $r_{2}>0$. Q.E.D.

Proof to proposition 4.7

Proof. Follows the proof for proposition 4.5.

Proof to proposition 4.8

Proof. Since we know agent $b$ is on the verge of default when $\bar{\mu}=C P_{s 2}$. Subtracting both sides with $b_{s 2}^{b}$, we have $\bar{\mu}-b_{s 2}^{b}=C P_{s 2}-b_{s 2}^{b}$. Combining the above equation and equation $\left(4.12^{*}\right)$, we get the proof.

Proof to lemma 4.2

Proof. When agent $b$ does not default, from proposition 4.4, we have $r_{s^{*}}=0, \forall s^{*} \in S^{*}$ and $\bar{r}=0$. From proposition 4.5 , we have $y_{s 2}^{a}=y_{s 2}^{b}=1$. The capital good sold by agent $a$ in state $s \in S$ is $q_{s 2}^{a}=\frac{b_{s 2}^{b}}{p_{s 2}}=y_{s 2}^{b}-y_{02}^{b}=1-y_{02}^{b}$. And with the binding budget constraints, $\left(s 1^{a}\right),\left(s 2^{a}\right),\left(s 1^{b}\right)$ and $\left(s 2^{b}\right)$ and market clearing conditions: $\frac{b_{s 2}^{b}}{p_{s 2}}=q_{s 2}^{a}$, 
$\frac{b_{s 1}^{a}}{p_{s 1}}=q_{s 1}^{b}, \frac{\bar{\mu}^{b}}{1+\bar{r}}=\bar{m}$ and $\frac{\mu_{s}^{a}+\mu_{s}^{b}}{1+r_{s}}=M_{s}$, we have $b_{s 2}^{b}=\mu_{s}^{a}, b_{s 1}^{a}=\mu_{s}^{b}, \mu_{s}^{b}=\frac{M_{s}+\bar{m}}{2}$, $\mu_{s}^{a}=\frac{M_{s}-\bar{m}}{2}$. In state $s$, agent $b$ will default on the collateralized loan in state $s$ when $p_{s 2} C<\bar{\mu}$. From the market clearing condition $\frac{b_{02}^{b}}{p_{02}}=q_{02}^{a}$, we have $C=\frac{b_{02}^{b}}{p_{02}}=q_{02}^{a}$. Hence $p_{s 2} C=\frac{b_{s 2}^{b}}{q_{s 2}^{a}} q_{02}^{a}=\frac{\frac{M_{s}-\bar{m}}{2}}{1-y_{02}^{b}} q_{02}^{a}=\frac{\frac{M_{s}-\bar{m}}{2}}{1-q_{02}^{a}} q_{02}^{a}<\bar{m}$, which is equivalent to $q_{02}^{a} \leq \frac{2 \bar{m}}{M_{s}+\bar{m}}$. Q.E.D.

We also derive here the following results which will be important later in the paper:

Since $y_{s 2}^{a}=y_{s 2}^{b}=1, \sigma=0.3$, and $B_{s}=1$, from equation $\left(4.12^{*}\right)$, we have $\frac{p_{s 2}}{p_{s 1}}=0.3\left(y_{s 2}\right)^{-0.7}=$ $0.3, \forall s \in S$, .

Since $p_{s 2}=\left(M_{s}-\bar{m}\right) /\left[2\left(1-q_{02}^{a}\right)\right]$, we have $p_{s 1}=p_{s 2} /\left(p_{s 2} / p_{s 1}\right)=\frac{M_{s}-\bar{m}}{0.6\left(1-q_{02}^{a}\right)}$

$q_{s 1}^{b}=\frac{\mu_{s}^{b}}{p_{s 1}}=0.3\left(1-q_{02}^{a}\right) \frac{M_{s}+\bar{m}}{M_{s}-\bar{m}}$

$x_{s}^{a}=\left(y_{s 2}^{a}\right)^{0.3}+q_{s 1}^{b}=1+0.3\left(1-q_{02}^{a}\right) \frac{M_{s}+\bar{m}}{M_{s}-\bar{m}}$

$x_{s}^{b}=\left(y_{s 2}^{b}\right)^{0.3}+q_{s 1}^{b}=1-0.3\left(1-q_{02}^{a}\right) \frac{M_{s}+\bar{m}}{M_{s}-\bar{m}}$

Proof to proposition 4.9

Proof. Step1: from the first order conditions of agent $b$ 's optimization problem w.r.t. $\bar{\mu}$, $b_{02}^{b}, \mu_{0}^{b}$ and $q_{01}^{b}$, we have:

$\frac{\lambda_{01}^{b}}{1+\bar{r}}=\lambda_{03}^{b}+\lambda_{05}^{b}$,

$\lambda_{01}^{b}=\frac{1}{p_{02}}\left[\frac{1}{x_{0}^{b}} B_{0} \sigma\left(y_{02}^{b}\right)^{\sigma-1}+\pi_{1} \frac{1}{x_{1}^{b}} B_{1} \sigma\left(y_{12}^{b}\right)^{\sigma-1}+\pi_{2} \frac{1}{x_{2}^{b}} B_{2} \sigma\left(y_{22}^{b}\right)^{\sigma-1}\right]$

$\frac{\lambda_{01}^{b}}{1+r_{0}}=\lambda_{02}^{b}$

$\lambda_{02}^{b} p_{01}=\frac{1}{x_{0}^{b}}$

From the first order conditions of agent $b$ 's optimization problem w.r.t. $\mu_{1}^{b}, q_{1}^{b}, \mu_{2}^{b}$ and $q_{2}^{b}$, we have

$$
\begin{aligned}
& \frac{\lambda_{03}^{b}}{\left(1+r_{1}\right)}=\lambda_{04}^{b} \\
& \lambda_{04}^{b} p_{11}=\pi_{1} \frac{1}{x_{1}^{b}} \\
& \frac{\lambda_{05}^{b}}{\left(1+r_{2}\right)}=\lambda_{06}^{b} \\
& \lambda_{06}^{b} p_{21}=\pi_{2} \frac{1}{x_{2}^{b}}
\end{aligned}
$$


Since $r_{s^{*}}=0, \forall s^{*} \in S^{*}, \pi_{1}=\pi_{2}=\frac{1}{2}, \sigma=0.3$, and $B_{S^{*}}=1, \forall s^{*} \in S^{*}$ We have

$\frac{1}{p_{01}} \frac{1}{x_{0}^{b}}=\frac{1}{2} \frac{1}{p_{11}} \frac{1}{x_{1}^{b}}+\frac{1}{2} \frac{1}{p_{21}} \frac{1}{x_{2}^{b}}$

$\frac{1}{p_{01}} \frac{1}{x_{0}^{b}}=0.3 \frac{1}{p_{02}}\left[\frac{1}{x_{0}^{b}}\left(q_{02}^{a}\right)^{-0.7}+\frac{1}{2} \frac{1}{x_{1}^{b}}+\frac{1}{2} \frac{1}{x_{2}^{b}}\right]$

Let

$k=\frac{1}{2} \frac{1}{p_{11}} \frac{1}{x_{1}^{b}}+\frac{1}{2} \frac{1}{p_{21}} \frac{1}{x_{2}^{b}}$

$t=0.3\left(\frac{1}{2} \frac{1}{x_{1}^{b}}+\frac{1}{2} \frac{1}{x_{2}^{b}}\right)$

The above two equations become:

(4.91) $\frac{1}{p_{01}} \frac{1}{x_{0}^{b}}=k$

(4.92) $\frac{1}{p_{01}} \frac{1}{x_{0}^{b}}=\frac{1}{p_{02}}\left[0.3 \frac{1}{x_{0}^{b}}\left(q_{02}^{a}\right)^{-0.7}+t\right]$

Step2: from the results that $r_{s^{*}}=0, \forall s^{*} \in S^{*}$ and $\bar{r}=0$, and the budget constraints and market clearing conditions: $\mu_{0}^{a}=p_{02} q_{02}^{a}, p_{02}=\frac{b_{02}^{b}}{q_{02}^{a}}, b_{02}^{b}=\frac{\mu_{0}^{b}}{1+r_{0}}+\frac{\bar{\mu}}{1+\bar{r}}, 1+\bar{r}=\frac{\bar{\mu}}{\bar{m}}$ and $1+r_{0}=\frac{\mu_{0}^{a}+\mu_{0}^{b}}{M_{0}}$, we have $\mu_{0}^{a}=\frac{M_{0}+\bar{m}}{2}$ and $\mu_{0}^{b}=\frac{M_{0}-\bar{m}}{2}$. We have $p_{02}^{a}=\frac{\mu_{0}^{a}}{q_{02}^{a}}=\frac{\left(M_{0}+\bar{m}\right)}{2 q_{02}^{a}}$, $p_{01}=\frac{\mu_{0}^{b}}{q_{01}^{b}}=\frac{\left(M_{0}-\bar{m}\right)}{2 q_{01}^{b}}$ and $x_{0}^{b}=\left(q_{02}^{a}\right)^{0.3}-q_{01}^{b}$.

Step3: substitute $p_{01}, p_{02}$ and $x_{0}^{b}$ into the two equations (4.91) and (4.92) in step 1. We have

$q_{01}^{b}=\frac{k\left(M_{0}-\bar{m}\right)\left(q_{02}^{a}\right)^{0.3}}{2+k\left(M_{0}-\bar{m}\right)}$

$q_{01}^{b}=\frac{0.3\left(q_{02}^{a}\right)^{0.3}+\left(q_{02}^{a}\right)^{1.3} t}{\left(M_{0}+\bar{m}\right)+q_{02}^{a} t\left(M_{0}-\bar{m}\right)}\left(M_{0}-\bar{m}\right)$

Combine the above two, we have

$(4.93) k\left[0.7 M_{0}+1.3 \bar{m}\right]=0.6+2 t q_{02}^{a}$

Let $J=\left[0.7 M_{0}+1.3 \bar{m}\right]$

Step4: substitute $k$ and $t$ into the equation (4.93) and simplify, and let $h=1-q_{02}^{a}$, we have a quadratic equations with one unknown,

$a_{1} h^{2}-a_{2} h+a_{3}=0$

$a_{1}, a_{2}$ and $a_{3}$ are all exogenous variables, where:

$a_{1}=\left(\left(M_{1}+\bar{m}\right)\left(M_{2}+\bar{m}\right) 0.3^{2}+\frac{1}{2}\left(M_{1}-\bar{m}\right)\left(M_{2}+\bar{m}\right) 0.3+\frac{1}{2}\left(M_{2}-\bar{m}\right)\left(M_{1}+\bar{m}\right) 0.3+\right.$

$\left.+J \frac{1}{2}\left(M_{2}+\bar{m}\right) 0.3+J \frac{1}{2}\left(M_{1}+\bar{m}\right) 0.3\right)$

$a_{2}=\left(\left(M_{1}+\bar{m}\right)\left(M_{2}-\bar{m}\right) 0.3\left(1+\frac{1}{2}\right)+\left(M_{1}-\bar{m}\right)\left(M_{2}+\bar{m}\right) 0.3\left(1+\frac{1}{2}\right)+\left(M_{1}-\bar{m}\right)\right.$ 


$$
\begin{aligned}
& \left.\left(M_{2}-\bar{m}\right)+J \frac{1}{2}\left(M_{2}-\bar{m}\right)+J \frac{1}{2}\left(M_{1}-\bar{m}\right)\right) \\
& a_{3}=2\left(M_{1}-\bar{m}\right)\left(M_{2}-\bar{m}\right)
\end{aligned}
$$

Step5: We resort to Mathematica to solve the above equations and have two roots $h_{1}$ and $h_{2}$. We want to check that there exists an $M_{0}^{*}$ where $0<q_{02}^{a}=\frac{2 \bar{m}}{M_{s}+\bar{m}}<1$, which is equivalent to $0<h=1-q_{02}^{a}=\frac{\left(-\bar{m}+M_{2}\right)}{\left(\bar{m}+M_{2}\right)}<1$. And $\frac{\partial q_{02}^{a}}{\partial M_{0}}>0$, which is equivalent to $\frac{\partial h}{\partial M_{0}}<0$.

Under the restriction $\bar{m}>0, M_{0}-\bar{m}>0, M_{1}-\bar{m}>0, M_{2}-\bar{m}>0$, and $M_{1}>M_{2}$. First, we take $h_{1}$ and verify that $h_{1}$ is positive. And there exists $\left\{\bar{m}, M_{1}, M_{0}, M_{2}\right\}$ such that $h_{1}<1$. We then also verify that there exist $\left\{\bar{m}, M_{1}, M_{0}, M_{2}\right\}$ such that $0<h_{1}=\frac{\left(-\bar{m}+M_{2}\right)}{\left(\bar{m}+M_{2}\right)}<1$. Then we also verify that $\frac{\partial h_{1}}{\partial M_{0}}<0$.

Under the same restriction, we can also verify that $h_{2}$ is positive and there exists $\left\{\bar{m}, M_{1}, M_{0}, M_{2}\right\}$ such that $h_{2}<1$. However, there does not exist $\left\{M_{1}, \bar{m}, M_{0}, M_{2}\right\}$ such that $h_{2}=\frac{\left(-\bar{m}+M_{2}\right)}{\left(\bar{m}+M_{2}\right)}$. What whatever $h_{2}$ might be, agent $b$ will never be on the verge of default. 